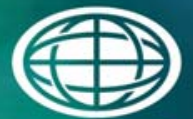

Savannah River

National Laboratory ${ }^{\mathrm{m}}$

OPERATED BY SAVANNAH RIVER NUCLEAR SOLUTIONS

\title{
Alternate Paddle Configuration for Improved Wear Resistance in the Saltstone Mixer
}

Marissa M. Reigel

Mark D. Fowley

September 2013

SRNL-STI-2013-00523 
SRNL-STI-2013-00523

Revision 0

\section{DISCLAIMER}

This work was prepared under an agreement with and funded by the U.S. Government. Neither the U.S. Government or its employees, nor any of its contractors, subcontractors or their employees, makes any express or implied:

1. warranty or assumes any legal liability for the accuracy, completeness, or for the use or results of such use of any information, product, or process disclosed; or

2. representation that such use or results of such use would not infringe privately owned rights; or

3. endorsement or recommendation of any specifically identified commercial product, process, or service.

Any views and opinions of authors expressed in this work do not necessarily state or reflect those of the United States Government, or its contractors, or subcontractors.

\section{Printed in the United States of America \\ Prepared for \\ U.S. Department of Energy}


Keywords: Saltstone, Mixer, Wear

Retention: Permanent

\section{Alternate Paddle Configuration for Improved Wear Resistance in the Saltstone Mixer}

M. M. Reigel

M. D. Fowley

September 2013

Prepared for the U.S. Department of Energy under contract number DE-AC09-08SR22470. 


\section{REVIEWS AND APPROVALS}

\section{AUTHORS:}

M. M. Reigel, Engineering Process Development

M. D. Fowley, Engineering Process Development

TECHNICAL REVIEW:

K. M. Fox, Engineering Process Development, Reviewed per E7 2.60

\section{APPROVAL:}

E. N. Hoffman, Manager

Date
Date

Date
Date

Engineering Process Development

S. L. Marra, Manager

Date

Environmental \& Chemical Process Technology Research Programs

J. S. Contardi, Manager

Date

Saltstone Facility Engineering 


\section{ACKNOWLEDGEMENTS}

The authors would like to acknowledge the help and advisement of Erich Hansen and Ken Imrich as well as the all the preparation work for this task by Vernon Bush and Mike Lee. 


\section{EXECUTIVE SUMMARY}

The Saltstone Production Facility has a 10-inch Readco-Kurimoto continuous mixer that mixes the premix dry feeds and low-level waste salt solution to make fresh (uncured) saltstone. Inspection of the mixer in January 2013 showed significant wear on the third, fourth and fifth paddle pairs after the conveying augers. A 2-inch Readco-Kurimoto continuous mixer was used to test alternate paddle configurations for use in the 10-inch mixer to decrease the wear rate on the paddles.

Two wear tests were conducted to investigate a method of reducing wear on the mixer paddles. The first test (wear test 2a) had a paddle configuration similar to the currently installed 10-inch mixer in the SPF. This test established baseline wear. The second test (wear test $2 \mathrm{~b}$ ) had a reconfigured paddle arrangement that replaced the flat paddles with helical paddles for paddle pairs $2-6$ and aligned paddle pair 1 with the augers. The intent of the reconfiguration was to more effectively convey the partially wetted dry feeds through the transition region and into the liquid feed where paddle wear is reduced due to dry feeds and salt solution being mixed at the intended water to premix ratio. The design of the helical paddles provides conveyance through the transition region to the liquid feed inlet. The alignment with the auger is aimed to provide a smoother transition (minimizing the discontinuity between the auger and paddle pair 1) into the downstream paddles.

A soft metal with low wear resistance (6000 series aluminum) was used for the wear testing paddles to determine wear patterns while minimizing run time and maximizing wear rate. For the two paddle configurations tested using the scaled 2-inch Readco-Kurimoto continuous mixer, with the first six paddles after the augers replaced by the wear paddles and the remaining paddles were stainless steel. Since the 10-inch SPF mixer is designed with the liquid inlet centered over paddle pairs 5 and 6 , the scaled 2-inch mixer was configured the same way.

The wear rate from wear test $2 \mathrm{a}$ was approximately double the wear rate from wear test $2 \mathrm{~b}$ for paddle pairs 4 and 5. For both configurations, there was little or no wear on paddle pairs 1, 2, 3 and 6 based on mass change, indicating that the un-wetted and fully wetted premix materials cause less wear than the partially wetted premix. Additionally, inspection of the wear surface of the paddles showed more deformation on the flat paddles than the helical paddles which was consistent with the wear rates. Aligning of the auger discharge flight with paddle pair 1 resulted in a lower wear rate paddle pair 1 rather than having them misaligned with the feed augers.

During the paddle wear tests, polishing wear was observed on the inside barrel of the mixer. The polishing wear is evident on the upper housing clamshell and the lower housing clamshell primarily at paddle pairs 4 and 5, which is the transition region of the mixer. Wear on the mixer barrel increases the space between the paddles and the barrel, resulting in increased grout build up on the barrel. Since the mixer barrel cannot be reconfigured or replaced in the SPF, the method for mitigating wear on the barrel is to move the more viscous grout through the transition region as quickly as possible. In addition, the location of the liquid inlet does not allow for sufficient cleaning of the mixer since residual grout remains on paddle pairs $1-4$. As the paddles continue to wear and the self-cleaning capability of the paddles is lost, the lack of sufficient flushing would aid in grout build up between the barrel and the paddles which could eventually lead to decreased throughput capacity of the dry feeds.

Changing the paddle configuration from flat to helical resulted in no change to the rheological properties of the grout mixture. Both tests produced a grout that is within the processing range of the SPF. 
Based on the results of this testing, it is recommended for the currently installed SPF mixer that paddle pairs 1 through 6 be helical rather than flat, with the paddle pair 1 aligned with the feed augers in order to minimize the wear occurring in the SPF mixer.

Based on the results of this testing, it is recommended that the mixer be inspected and critical measurements be taken whenever the SPF processing schedule allows in order to establish a wear rate of the 10-inch mixer paddles. ${ }^{5}$ Based on these measurements, the lifetime of paddles in the transition region can be established in order to set up a maintenance schedule for the mixer. Since replacing the entire mixer is very expensive and time intensive, replacing the worn paddles after a specific time period would allow for planned shutdowns as well as process optimization such that the mixer throughput is not compromised.

In addition, further testing should be performed to determine an alternate liquid inlet location to better flush the mixer of residual grout at the end of processing. Sufficiently cleaning the mixer will help eliminate another potential source of wear. Another potential method for reducing the wear rate in the mixer is to reduce the mixer speed without affecting the throughput capacity. Since wear rate is a function of impact velocity of the grout and mixing paddles, testing could be done using the 2-inch mixer determine the optimum mixer speed to reduce wear but not adversely impact facility operations (e.g. throughput capacity and grout properties). 


\section{TABLE OF CONTENTS}

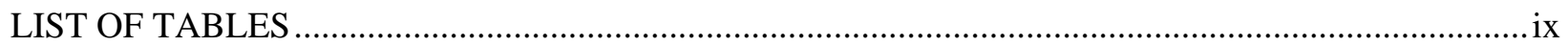

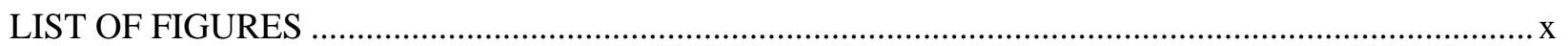

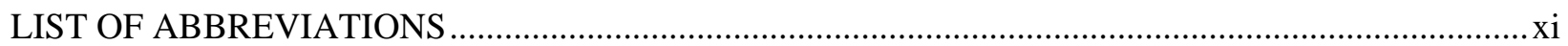

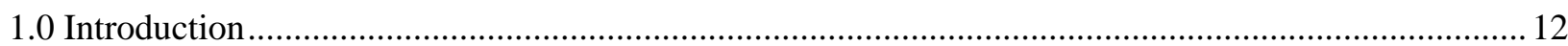

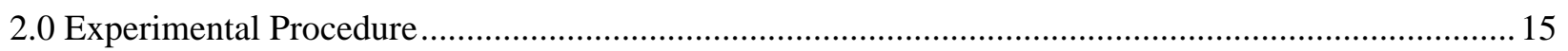

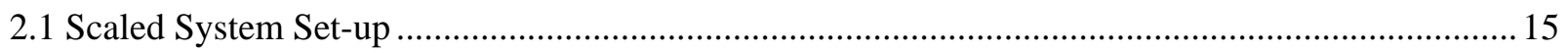

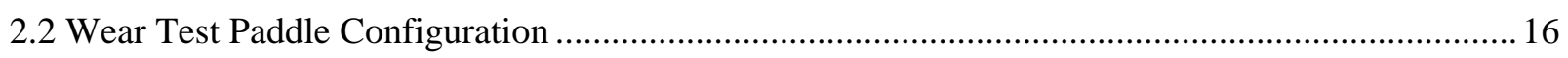

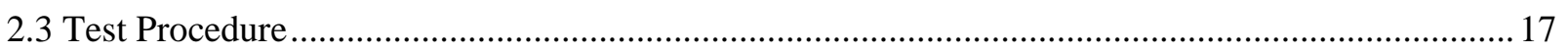

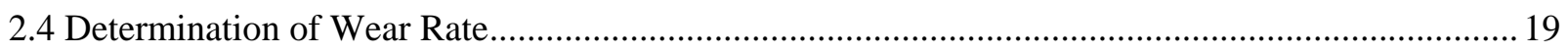

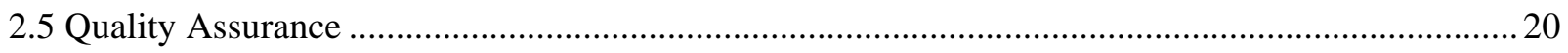

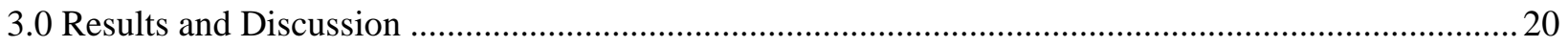

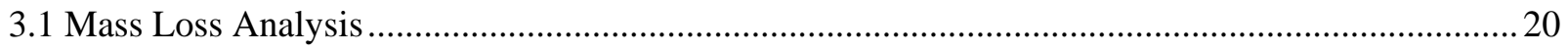

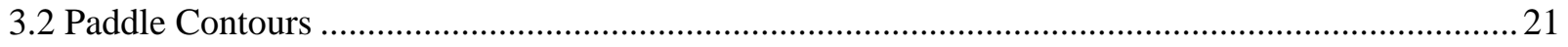

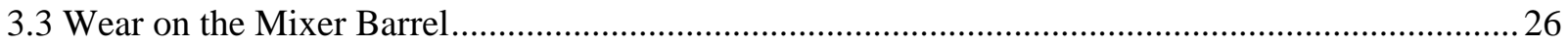

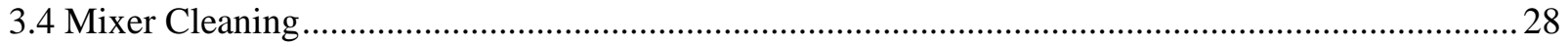

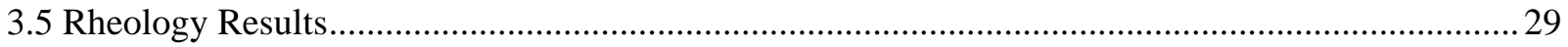

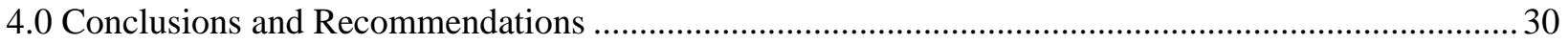

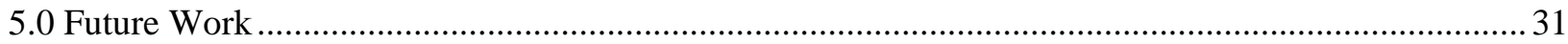

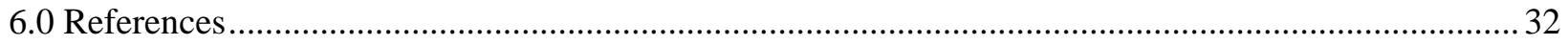




\section{LIST OF TABLES}

Table 1-1. Paddle to inside barrel clearances as measured during January 2013 inspection ..................... 15

Table 1-2. Machined tolerances in the 10 -inch Readco-Kurimoto continuous mixer ...............................15

Table 2-1. Testing conditions for the 2 inch mixer compared to the 10 inch mixer ................................18

Table 3-1. Wear on paddle tips for paddle pairs 4 and 5 after testing. ..................................................25

Table 3-2. Rheological properties of the wear tests ............................................................................ 29 


\section{LIST OF FIGURES}

Figure 1-1. 10-inch Readco-Kurimoto mixer installed in the SPF showing the feed augers and the corotating shafts containing pairs of intermeshing mixing paddles.

Figure 1-2. A portion of the 10-inch mixer paddle configuration installed in the SPF in December 2011.13

Figure 1-3. Two types of paddles shearing or flat (left) and conveying or helical (right) for the ReadcoKurimoto continuous mixer.

Figure 1-4. Paddles 1 - 9 in the 10-inch mixer after cleaning during the January 2013 inspection with worn paddle tips showing on paddles 3 and 4 .

Figure 2-1. SRNL Scaled Continuous Processing Facility as configured for wear testing (dashed lines indicate instruments and collections points for the data acquisition system) ................................... 16

Figure 2-2. Paddle configuration for the mixer currently installed in the SPF (note the helical paddles at paddle pair 1 and the misalignment with the auger).....

Figure 2-3. Second paddle configuration with aluminum helical paddles at paddle pairs 1 - 6 (outlined) after the feed augers and stainless steel paddles for paddle pairs $7-26$.

Figure 2-4. Paddle fixture for measuring critical paddle dimensions …................................................ 19

Figure 2-5. Paddle angular position for the measuring fixture 20

Figure 3-1. Mass loss for paddle pairs 1 - 6 after wear testing in the SPF mixer configuration (2a) and the alternate helical paddle configuration (2b).

Figure 3-2. Pre- and post-test contour plot for wear test 2a, paddle 4 on the east shaft (flat paddle \#35).. 23

Figure 3-3. Pre-and post-test contour plot for wear test 2b, paddle 4 on the east shaft (helical paddle \#52)

Figure 3-4. Wear on the inner diameter of the (a) upper and (b) lower clamshells. ................................. 27

Figure 3-5. Wear on the inner diameter of the upper clamshell of the 10 -inch SPF mixer. ...................... 27

Figure 3-6. Extent of cleaning in the 2-inch mixer due to flushing using the liquid inlet. ....................... 28

Figure 3-7. Thickness of grout build up (approximately 1.5 inches) in January 2013 on the inside diameter of the upper clamshell of the 10 -inch SPF mixer. 


\section{LIST OF ABBREVIATIONS}

$\begin{array}{ll}\text { ELAWD } & \text { Enhanced Low Activity Waste Disposal } \\ \text { HMI } & \text { Human Machine Interface } \\ \text { lbs } & \text { pounds } \\ \text { LLW } & \text { Low-level waste } \\ \text { rpm } & \text { revolutions per minute } \\ \text { SCPF } & \text { Scaled Continuous Processing Facility } \\ \text { SDF } & \text { Saltstone Disposal Facility } \\ \text { SDU } & \text { Saltstone Disposal Unit } \\ \text { SPF } & \text { Saltstone Production Facility } \\ \text { SRNL } & \text { Savannah River National Laboratory } \\ \text { SRS } & \text { Savannah River Site }\end{array}$

TTQAP Task Technical and Quality Assurance Plan 


\subsection{Introduction}

At the Savannah River Site (SRS), the Saltstone Production Facility (SPF) receives low level waste (LLW) salt solution from Tank $50 \mathrm{H}$ for treatment and disposal. At the SPF, the LLW is mixed with premix (a mixture of portland cement, blast furnace slag, and Class F fly ash) in a 10inch Readco-Kurimoto continuous mixer to produce fresh (uncured) saltstone that is transferred to the Saltstone Disposal Facility (SDF) for permanent disposition in the Saltstone Disposal Units (SDU).

The 10-inch Readco-Kurimoto mixer installed in the SPF is a continuous co-rotating twin-screw mixer. The co-rotating shafts contain multiple intermeshing lens-shaped mixing paddles that have tight clearances between the paddles and the inside diameter of the barrel which promotes a "selfwiping" capability. Also on the shafts are augers that provide the flow of premix into the paddles and they also have the tight clearance between the outside flight diameter and barrel. As shown in Figure 1-1, the paddles on the co-rotating shafts are paired and off-set by ninety degrees. For the duration of this report, the paddles at each position in the mixer will be referred to as paddle pair and the respective position number.

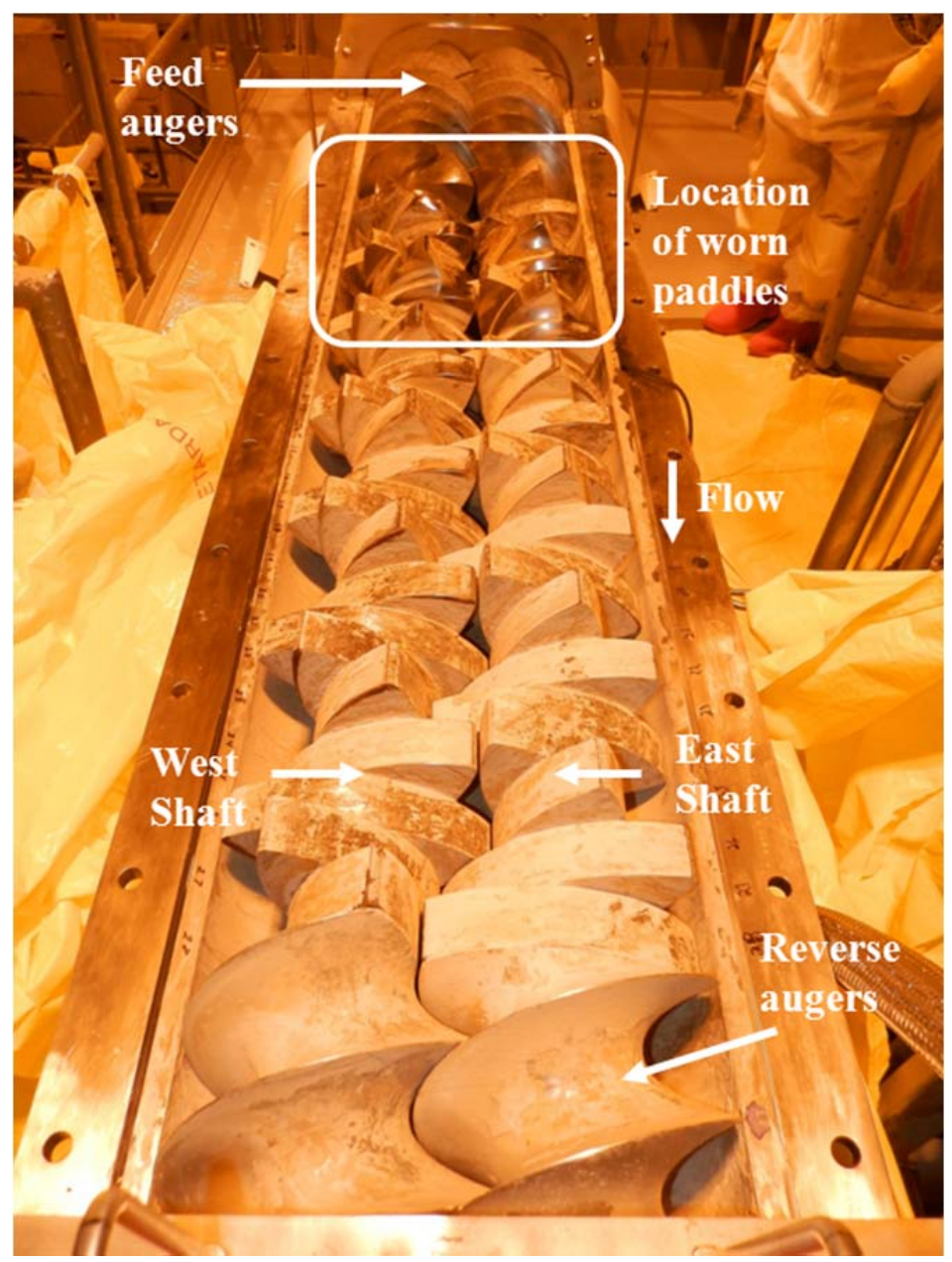

Figure 1-1. 10-inch Readco-Kurimoto mixer installed in the SPF showing the feed augers, the co-rotating shafts with pairs of intermeshing mixing paddles, and location of worn paddles. 
In December 2011, the saltstone mixer was removed from service and replaced with a new 10-inch Readco-Kurimoto continuous mixer as part of the Enhanced Low Activity Waste Disposal (ELAWD) changes to the SPF. In FY2012, SRNL tested the actual and SRNL recommended paddle configuration of the mixer removed from the SPF as part of the ELAWD project. ${ }^{1}$ The new mixer installed in the SPF as part of ELAWD has a different configuration; specifically the liquid inlet location is above paddle pairs 5 and 6 rather than above paddle pairs 1 and 2 as in the previous mixer design. The new design also includes a longer feed auger section and 28 paddle pairs rather than 26 in the previous design. ${ }^{1}$ Reverse augers replace the pair of reverse helical paddles in the previous design at the discharge of the mixer. The mixer configuration currently installed in the SPF is the focus of this report (Figure 1-2), specifically paddle pairs $1-6$.

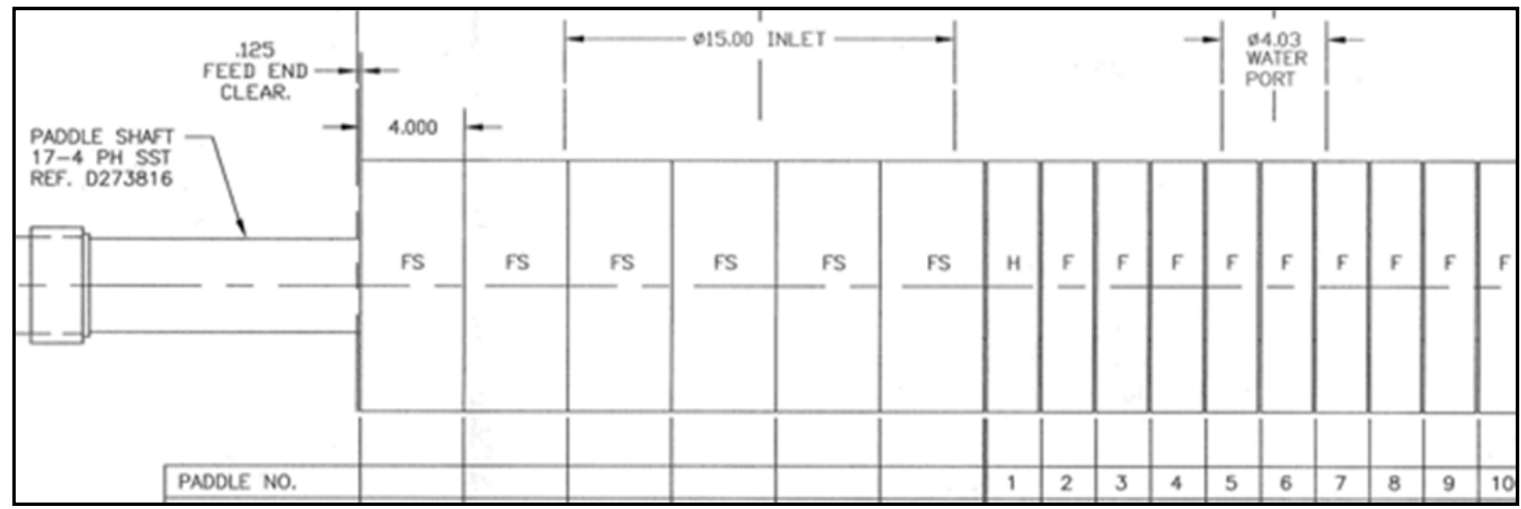

Figure 1-2. A portion of the 10-inch mixer paddle configuration installed in the SPF in December 2011.

The SPF mixer contains shearing and conveying paddles (Figure 1-3). The shearing paddles are flat and designed for mixing the constituents in the mixer. The conveying paddles have a helical curvature and are designed to help move the material through the mixer. Throughout this report, the shearing and conveying paddles will be referred to as flat and helical paddles, respectively.

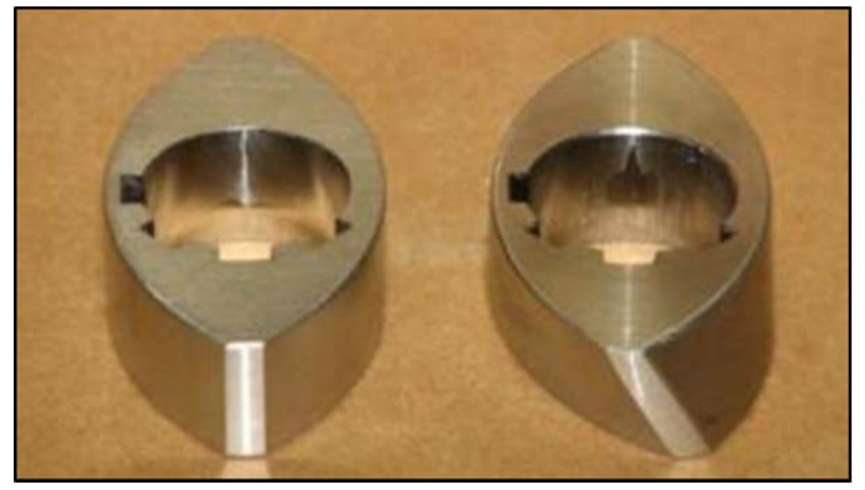

Figure 1-3. Two types of paddles shearing or flat (left) and conveying or helical (right) for the Readco-Kurimoto continuous mixer

In January 2013, a routine inspection of the SPF mixer showed there was more wear on the mixer paddles below the liquid inlet than what was anticipated based on previous mixer inspections and testing at Savannah River National Laboratory (SRNL) (Figure 1-4). As a result of this increased 
wear on paddles in the transition region of the mixer, SRNL was asked to evaluate the currently installed mixer paddle configuration to establish a wear baseline and propose alternate paddle and auger configurations to reduce the wear rate in the mixer. ${ }^{2}$ The transition region is defined as the area in the mixer where the dry feeds first become wetted by the LLW salt solution but before the dry feeds are completely wetted at the desired water to premix ratio. As documented in the Task Technical and Quality Assurance Plan (TTQAP), SRNL will test paddle configurations that are expected to reduce the wear rate on the paddles based on results of the FY2012 testing. ${ }^{3}$ The wear testing is executed using the Scaled Continuous Processing Facility (SCPF) at SRNL. ${ }^{1,4}$

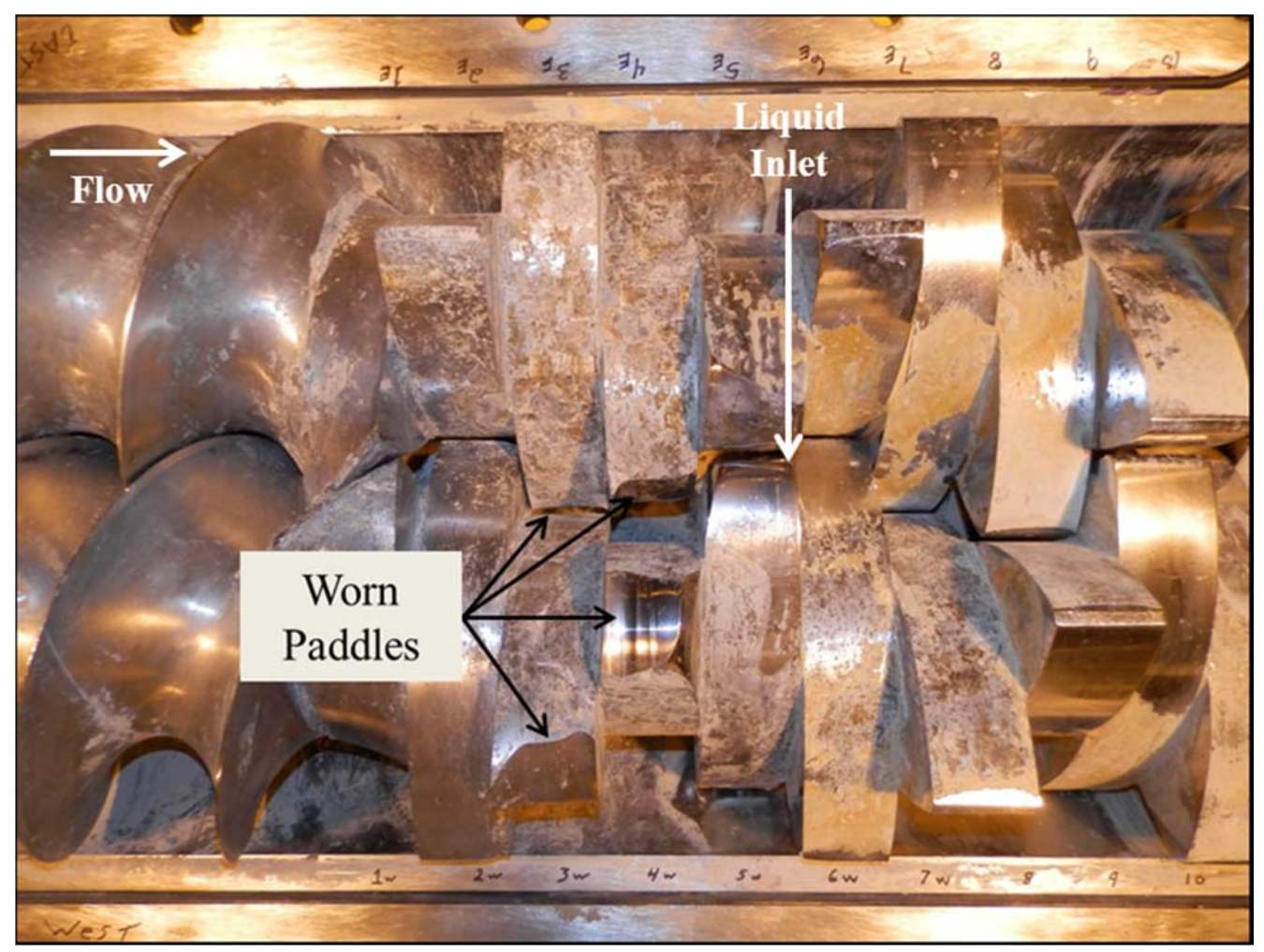

Figure 1-4. Paddles 1 - 9 in the 10-inch mixer after cleaning during the January 2013 inspection with worn paddle tips showing on paddles 3 and 4.

During the mixer inspection in January 2013, pictures and measurements were taken of the paddles. The clearances between paddle pairs $1-7$ and the inside barrel were measured and documented (Table 1-1). These paddles were selected since they were anticipated to have the most wear based on the location of the liquid inlet. ${ }^{5}$ Other selected paddles were measured during the inspection to determine whether wear was occurring elsewhere in the mixer. The as-machined clearances for the as-built 10-inch Readco-Kurimoto mixer are shown in Table 1-2. Comparing the measured gap distances in Table 1-1 to the machined paddle to barrel wall tolerance in Table 1-2, paddle pairs 3, 4, and 5 on both the east and west side show the most wear. The clearances between the paddle tip and the barrel wall for paddle pairs 1, 2, 6, and 7 fell within or close to the machined tolerances of the 10-inch mixer. Selected paddles in the rest of the mixer (paddle pairs $8-26$ ) had little or no change in the clearance and were within the specified tolerance listed in Table 1-2. 
SRNL-STI-2013-00523

Revision 0

Table 1-1. Paddle to inside barrel clearances as measured during January 2013 inspection

\begin{tabular}{|c|c|c|c|c|c||}
\hline \multicolumn{2}{|c|}{ Paddle No. } & $\mathbf{1}$ & $\mathbf{2}$ & $\mathbf{3}$ & $\mathbf{4}$ \\
\hline \multirow{2}{*}{$\begin{array}{c}\text { Measured } \\
\text { Gap (in) }\end{array}$} & East & 0.125 & 0.125 & $0.125-0.250$ & $0.687-1.125$ \\
\cline { 2 - 6 } & West & 0.125 & $0.125-0.312$ & $0.312-1.0$ & $0.812-1.062$ \\
\hline \multicolumn{2}{|c|}{ Paddle No. } & $\mathbf{5}$ & $\mathbf{6}$ & $\mathbf{7}$ & \\
\hline \multirow{2}{*}{$\begin{array}{c}\text { Measured } \\
\text { Gap (in) }\end{array}$} & East & $0.125-0.375$ & 0.125 & 0.125 & \\
\cline { 2 - 5 } & West & $0.187-0.250$ & 0.187 & 0.125 & \\
\hline
\end{tabular}

Table 1-2. Machined tolerances in the 10-inch Readco-Kurimoto continuous mixer

\begin{tabular}{|c|c||}
\hline Clearance Locations & Tolerance (in) \\
\hline Screw to screw & 0.020 \\
\hline Paddle to paddle & $0.095-0.155$ \\
\hline Paddle to barrel wall & $0.110-0.145$ \\
\hline Screw to barrel wall & $0.110-0.140$ \\
\hline
\end{tabular}

\subsection{Experimental Procedure}

\subsection{Scaled System Set-up}

SRNL has developed a pilot scale system of the SPF at Savannah River Site (SRS) known as the Scaled Continuous Processing Facility (SCPF) (Figure 2-1). ${ }^{4}$ The scaled system consists of a Mechatron "MC" dry material feeder coupled to a Readco-Kurimoto 2-inch co-rotating twinscrew continuous processor (mixer) which mixes the dry feeds with liquid supplied by a feed tank. The liquid inlet on the 2-inch mixer was located on the top of the mixer over paddle pairs 5 and 6 , centered between the east and west shafts to mimic the 10-inch mixer configuration in the SPF. Grout is made from the mixing of the dry feeds with water and is discharged from the end of the mixer into a receipt tank (grout drum). Water was used for this testing rather than salt solution due the expense of batching salt solution. In addition, it has been shown in previous testing that corrosion is not a cause of wear in the mixer, so salt solution is not required to determine the relative wear of the two paddle configurations. ${ }^{6}$

Details of the unit operations of the SCPF as well as the scaling and comparisons between the 2inch and 10-inch mixers are captured in other reports. ${ }^{1,4,7}$ For the wear testing, the feeder was operated in the gravimetric mode; the helix motor was set to provide the required dry feed rate based on mass loss in the hopper. In gravimetric mode, the helix auger is continuously feeding material into the dry feed chute. A $1 / 4$ " mesh screen fitted over the discharge tube of the feeder delivered dry feed evenly and without clumps. 


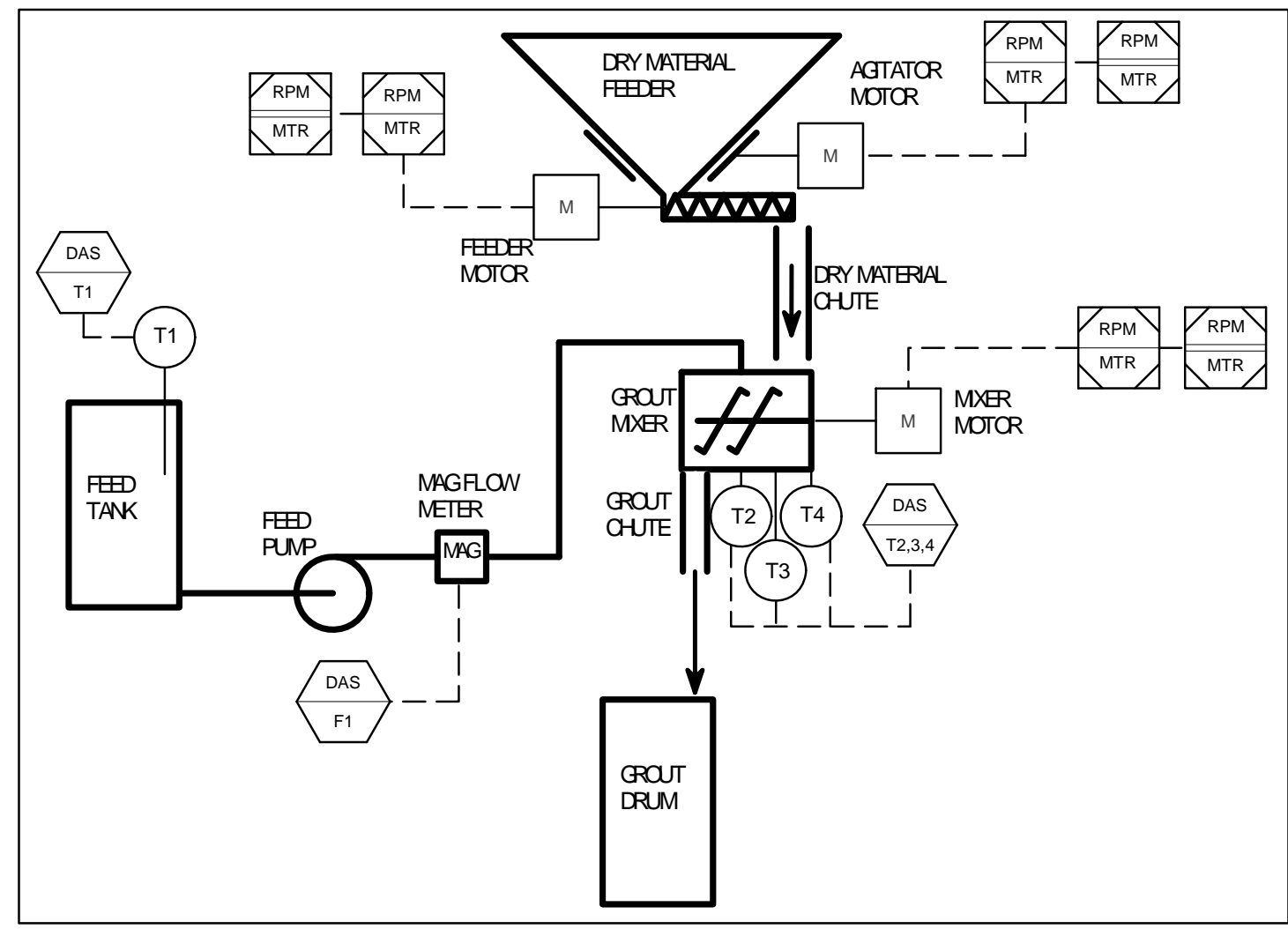

Figure 2-1. SRNL Scaled Continuous Processing Facility as configured for wear testing (dashed lines indicate instruments and collections points for the data acquisition system)

\subsection{Wear Test Paddle Configuration}

Based on the wear observed during the January 2013 SPF mixer inspection, paddle pairs $1-6$ showed moderate to extreme wear while paddle pairs $7-28$ showed no significant wear. For this testing, the 2-inch stainless steel paddle pairs $1-6$ were replaced with aluminum wear paddles. The wear paddles were fabricated out of 6000 series aluminum in order to increase the paddle wear rate ${ }^{8}$ and decrease the test run time, since 6000 series aluminum is a soft metal with low wear resistance. Each wear paddle was laser etched with a unique number to aid in reassembly and identification post testing.

Two paddle configurations were tested using the 2-inch mixer. The first paddle configuration tested was the same as the 10-inch mixer configuration currently installed in the SPF (Figure 1-2) to provide baseline wear. The feed augers were followed by a helical paddles at paddle pair 1 and flat paddles at paddle pairs $2-25$, ending with a reverse helical paddle at paddle pair 26 . The helical paddles at paddle pair 1 are offset at a 45 degree angle to the last flight of the auger, creating a misalignment in the flow path of the dry feeds from the auger into the mixer barrel (Figure 2-2). The reverse helical paddles conveyed the grout in the reverse direction away from the seals at the end of the shaft and aided in discharging the grout from the mixer. It should be noted that the 2-inch mixer cannot be configured with the reverse auger due to available space in the mixer barrel.

The second configuration was based on SRNL recommendations from paddle configuration testing performed in 2012. ${ }^{1}$ This configuration consists of helical paddles for paddle pairs $1-6$ 
followed by flat paddles at paddle pairs 7 - 25 (Figure 2-3). The helical paddles at paddle pair 1 are aligned with the end of the feed augers. The intent of the reconfigurations was to more effectively convey the partially wetted dry feeds through the transition region and into the liquid feed where paddle wear is reduced due to the lubricating effects of the liquid feed. The alignment with the auger is aimed to provide a smoother transition (minimizing the discontinuity between the auger and paddle pair 1) into the paddles and the helical paddles should provide conveyance through the transition region to the liquid feed inlet. The reverse helical paddles are at paddle pair 26. It should be noted that the current SPF mixer has 28 paddle pairs as part of the new design; however, the 2-inch mixer barrel cannot be changed to include more paddles. The difference of two paddle pairs between the 2-inch and 10-inch mixer will not impact the testing as well as the conclusions and recommendations made in this report.

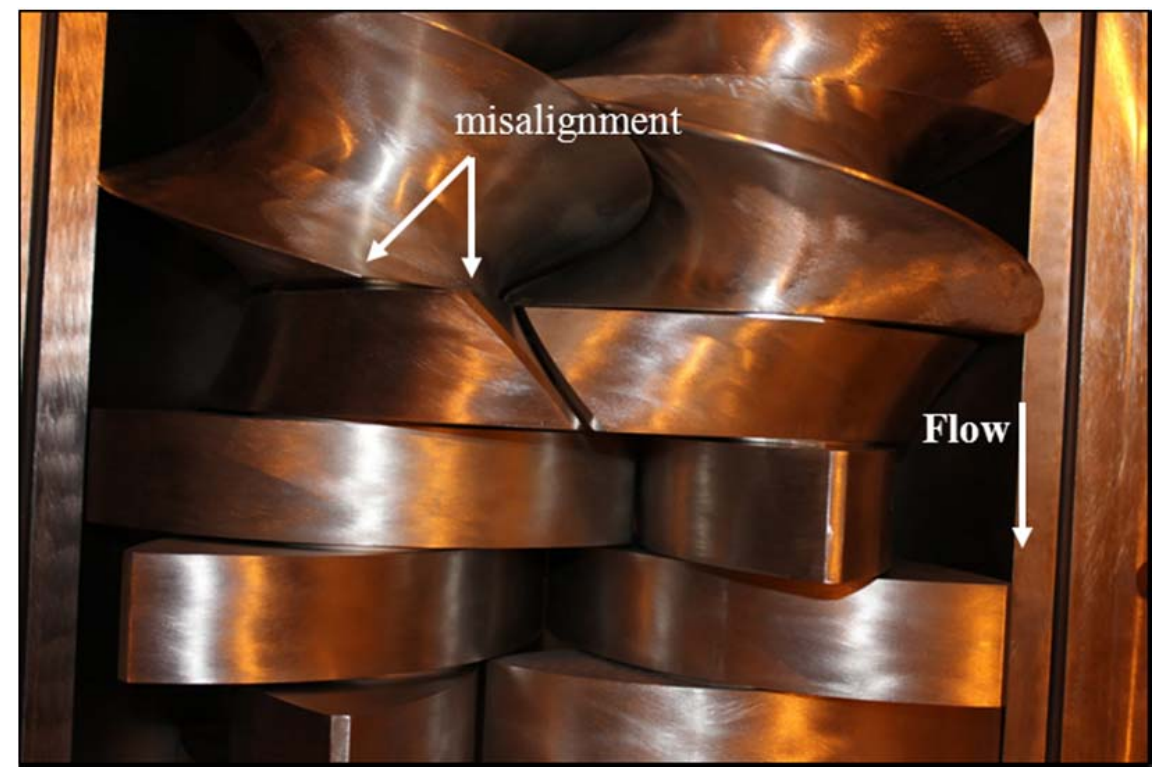

Figure 2-2. Paddle configuration for the mixer currently installed in the SPF (note the helical paddles at paddle pair 1 and the misalignment with the auger).

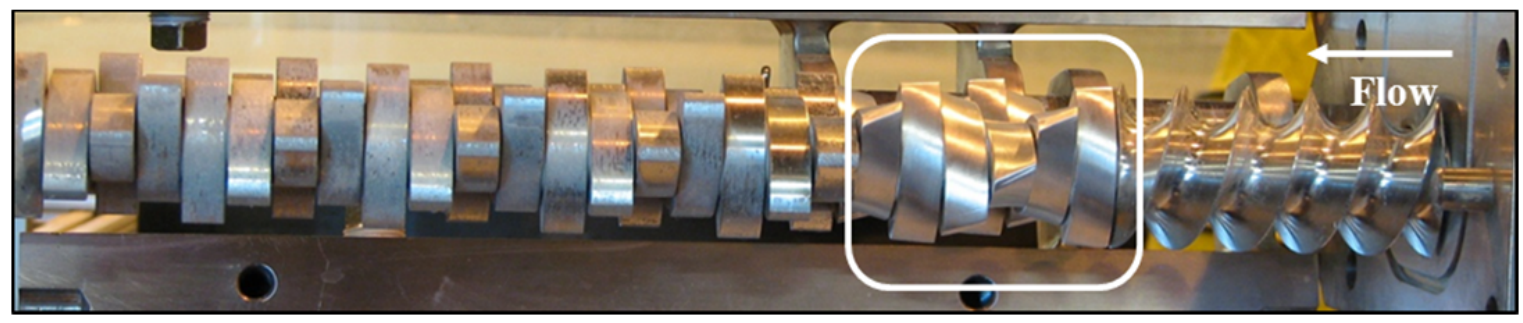

Figure 2-3. Second paddle configuration with aluminum helical paddles at paddle pairs 1 - 6 (outlined) after the feed augers and stainless steel paddles for paddle pairs $7-26$.

\subsection{Test Procedure}

The testing procedure started by filling the liquid feed tank and loading the dry feed hopper. The dry feed for the wear testing was a mixture of $45 \mathrm{wt} \%$ fly ash and $45 \mathrm{wt} \%$ blast furnace slag and $10 \mathrm{wt} \%$ cement. Approximately 50 gallons of process water and 400 lbs of dry material were loaded into their respective vessels. Dry material was loaded into eight heavy ply plastic bags (50 
pounds each), which were palletized and lifted to the top of the feeder using a fork truck. Each bag was emptied into the feed hopper. The 400 lbs of dry material filled the 8.7 cubic foot hopper to the top. The SPF operates at a dry feed throughput of approximately 35 tons/hour with the maximum throughput capacity of 50 tons/hr. For this testing, the SCPF dry feeder was run at a dry feed rate scaled to the maximum throughput capacity of the 10 -inch mixer ${ }^{9}$ (Table 2-1).

The liquid feed was started followed by the 2-inch mixer and both were adjusted to their respective test conditions (Table 2-1). The liquid feed rate was maintained to produce a 0.60 water to premix grout, similar to SPF operations. The mixer motor speed was set to $220 \mathrm{rpm}$ (307 rpm paddle speed) to provide maximum throughput for this testing. Grout production started when the dry material feeder was started.

Table 2-1. Testing conditions for the 2 inch mixer compared to the 10 inch mixer

\begin{tabular}{||c|c|c||}
\hline Operating Parameter & 10-inch & 2-inch \\
\hline \hline Maximum dry feed rate (lbs/hr) & 100,000 & 833.3 \\
\hline Mixer (paddle/auger) speed (rpm) & 232 & 307 \\
\hline Target w/p ratio & $0.60 \pm 0.01$ & $0.60 \pm 0.01$ \\
\hline
\end{tabular}

At the dry feed rate of $833.3 \mathrm{lbs} / \mathrm{hr}$, a full hopper lasted about 30 minutes. Due to the complexity of the reloading process, the system was shut down to assure personnel safety. The shut-down procedure reverses the startup process. The dry feeder was stopped, then after a moment the mixer, and after another moment the liquid feed. The liquid feed was allowed to run for approximately two minutes after stopping the dry feed to flush the majority of the grout out of the mixer. The filling, running, and stopping procedure was repeated until the desired mass of processed dry feeds was reached (3000 lbs). Once the test was completed, the system was put into a safe condition and the mixer was opened to remove the paddles for inspection. The mixer housing opens like a clamshell to fully expose the shaft for inspection, cleaning, or paddle replacement.

During each half hour grout run, at least one sample of the grout was taken at the discharge of the mixer. Fresh properties - rheological flow curve and flowability - were measured for each sample in order to determine if the alternate paddle configuration (wear test $2 \mathrm{~b}$ ) adversely impacts the grout. Rheological flow curves were obtained using a Haake VT550 rotoviscometer equipped with a stationary sample cup and a rotating MVII bob. This instrument has a smooth wall coaxial cylindrical geometry. ${ }^{10,11}$ The flow between the two concentric cylinders is characterized by measuring the torque and rotational speed of the inner cylinder. The torque readings were converted to shear stress and the speed to shear rate. Flow curves (up and down) were generated over a shear rate range of 0 to $300 \mathrm{sec}^{-1}$. Each curve took 150 seconds to accelerate/decelerate. After accelerating to $300 \mathrm{sec}^{-1}$, the shear rate was held for 30 seconds prior to decelerating. The down curves for saltstone grouts have been typically analyzed due to their thixotropic properties and fitted to a Bingham Plastic rheological model. The Bingham Plastic equation used to calculate the plastic viscosity and yield stress using the flow curve data is presented elsewhere. ${ }^{11}$

Following a test, the paddles were cleaned before inspection to remove residue. Residue was removed by soaking the wear paddles in concentrated nitric acid for 2 minutes. This process was carefully evaluated to verify residue removal with minimal aluminum removal. Numerous tests revealed that the aluminum lost during this process was relatively insignificant ( $>0.001$ grams) while the majority of the residue was removed. 


\subsection{Determination of Wear Rate}

The critical dimensions of each paddle were measured prior to being placed on the mixer shafts. The contour of each paddle was measured with a specially designed fixture ${ }^{\mathrm{a}}$ consisting of a micrometer and a rotary table (Figure 2-4) and the length, width, and height of each paddle was measured with a vernier caliper.

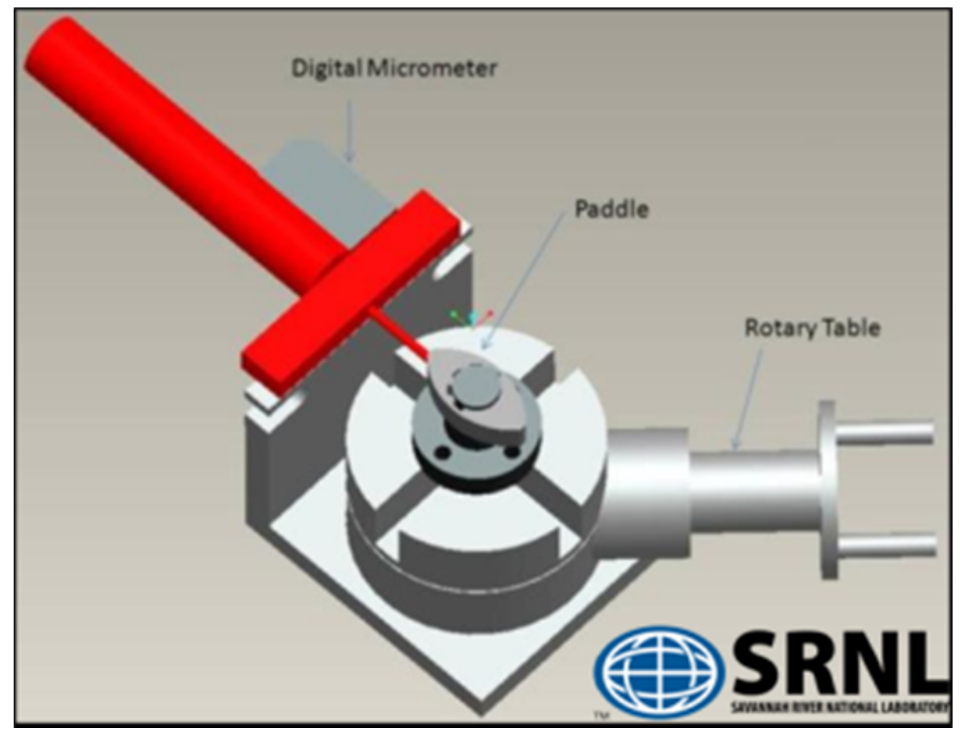

Figure 2-4. Paddle fixture for measuring critical paddle dimensions

The paddle fixture measured the radial dimension of the paddle contour at various angular locations around the paddle. In addition, the contour measurements were taken at three locations along the thickness of the paddle: bottom, middle, and top. Figure 2-5 defines the angular position relative to the paddle contour. Readings were concentrated around the tips $\left(90^{\circ}\right.$ and $\left.270^{\circ}\right)$ since it was expected that the majority of the wear would occur in those locations. The micrometer was zeroed on the fixture shaft and the micrometer reading plus the shaft radius provided the radial dimension of the paddle. The radial dimension and the angular location provided polar coordinates that defined the contour of the paddle. The polar coordinates were translated to Cartesian coordinates and plotted to provide before and after comparisons.

The precision of the micrometer is $+/-0.0006$ inches. The uncertainty of the radial measurement due to the rotary table was determined by comparing multiple measurements of the same paddle over a time period spanning the tests. At angular locations where the micrometer plunger was normal or nearly normal to the paddle surface (tips and sides) the uncertainty was $+/-0.002$ inches. At angular locations where the micrometer plunger was contacting the surface at a steep slope (sides around either tip) the uncertainty was $+/-0.007$ inches.

\footnotetext{
${ }^{a}$ Designed by Kevin Hera of SRNL EES/EED
} 
SRNL-STI-2013-00523

Revision 0

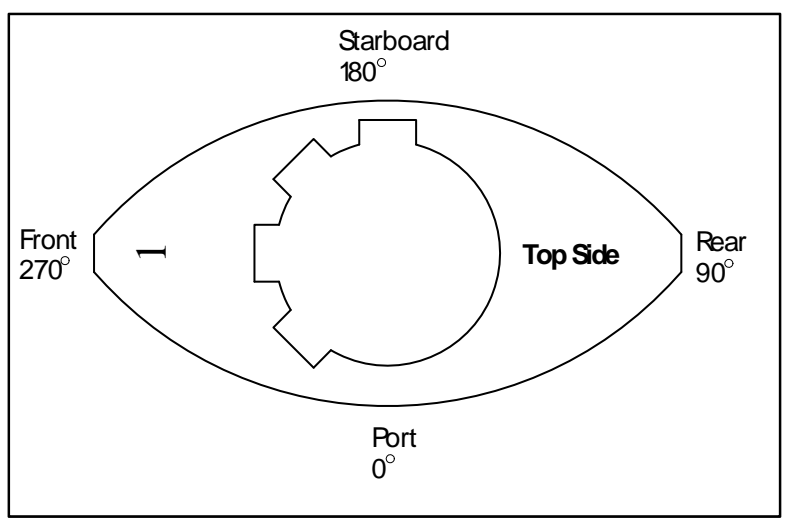

Figure 2-5. Paddle angular position for the measuring fixture

The mass of each paddle was measured with a balance before and after each test to quantify the amount of mass lost. Prior to weighing, the paddles were cleaned with warm water and a mild detergent to remove oil or grime and then dried with a towel. The precision of the balance was $+/-0.0006$ grams. Prior to each use the balance was checked with a calibrated weight set to verify that its response was within the stated accuracy. Given the tolerance of the balance and the assessment of aluminum lost during the cleaning process, the uncertainty of the mass measurement was estimated to be $+/-0.002$ grams.

To document the wear pattern on each paddle, a photograph of each wear paddle was taken before and after testing using a digital camera.

\subsection{Quality Assurance}

Requirements for performing reviews of technical reports and the extent of review are established in manual E7 2.60. SRNL documents the extent and type of review using the SRNL Technical Report Design Checklist contained in WSRC-IM-2002-00011, Rev. 2.

\subsection{Results and Discussion}

The total duration of each wear test was based on mass of dry feeds processed so that all the paddles were exposed to the same amount of material. The target dry feed mass for each wear test was 3000 pounds of premix. Wear test 2a processed $2975 \mathrm{lbs}$ of premix and wear test $2 \mathrm{~b}$ processed 3000 lbs of premix.

\subsection{Mass Loss Analysis}

The majority of the mass loss occurred in paddle pairs 4 and 5 for the baseline wear test (2a) as well as the alternate helical configuration (2b) (Figure 3-1). This is expected based on the clearance measurements taken from the 10-inch SPF mixer. As shown in Figure 1-2, the liquid inlet is centered over paddle pairs 5 and 6; however since the liquid wicks back towards the dry feed augers, the transition region occurs where the dry feeds are first wetted over paddle pairs 3 and 4 in the 10-inch mixer. The flat paddles used in wear test 2a are designed to shear rather than convey material, so the viscous and abrasive grout in the transition region has no directional force to move through the mixer other than additional material supplied by the augers. Therefore, it can be assumed that the viscous mixture imparts more force on the paddles in the transition region, causing more wear on the shearing (flat) paddles than it would if a conveying (helical) paddle replaced the flat paddle due to the inherent design of the paddles (Figure 1-3). For wear test 2b, it is hypothesized that the viscous mixture is conveyed through the transition region past the liquid 
inlet by the helical paddles, reducing the contact force and time with the paddles, resulting in a lower mass loss. The mass loss is presented as a wear rate in Figure 3-1 which demonstrates how destructive the thick grout mixture is at paddle pairs 4 and 5 as opposed to the fully wetted grout over paddle pair 6 and the dry feed at paddle pairs 1 - 3 .

As shown in Figure 3-1, the mass loss and subsequent wear rate on paddle pair 1 is more in wear test $2 \mathrm{a}$ than $2 \mathrm{~b}$. It is hypothesized that this is primarily due to the misalignment of the helical paddles with the augers in the current saltstone mixer. As demonstrated by this testing, as well as the testing in 2012, aligning paddle pair 1 in the mixer with the discharge of the feed augers reduces the wear on those paddles. ${ }^{1}$

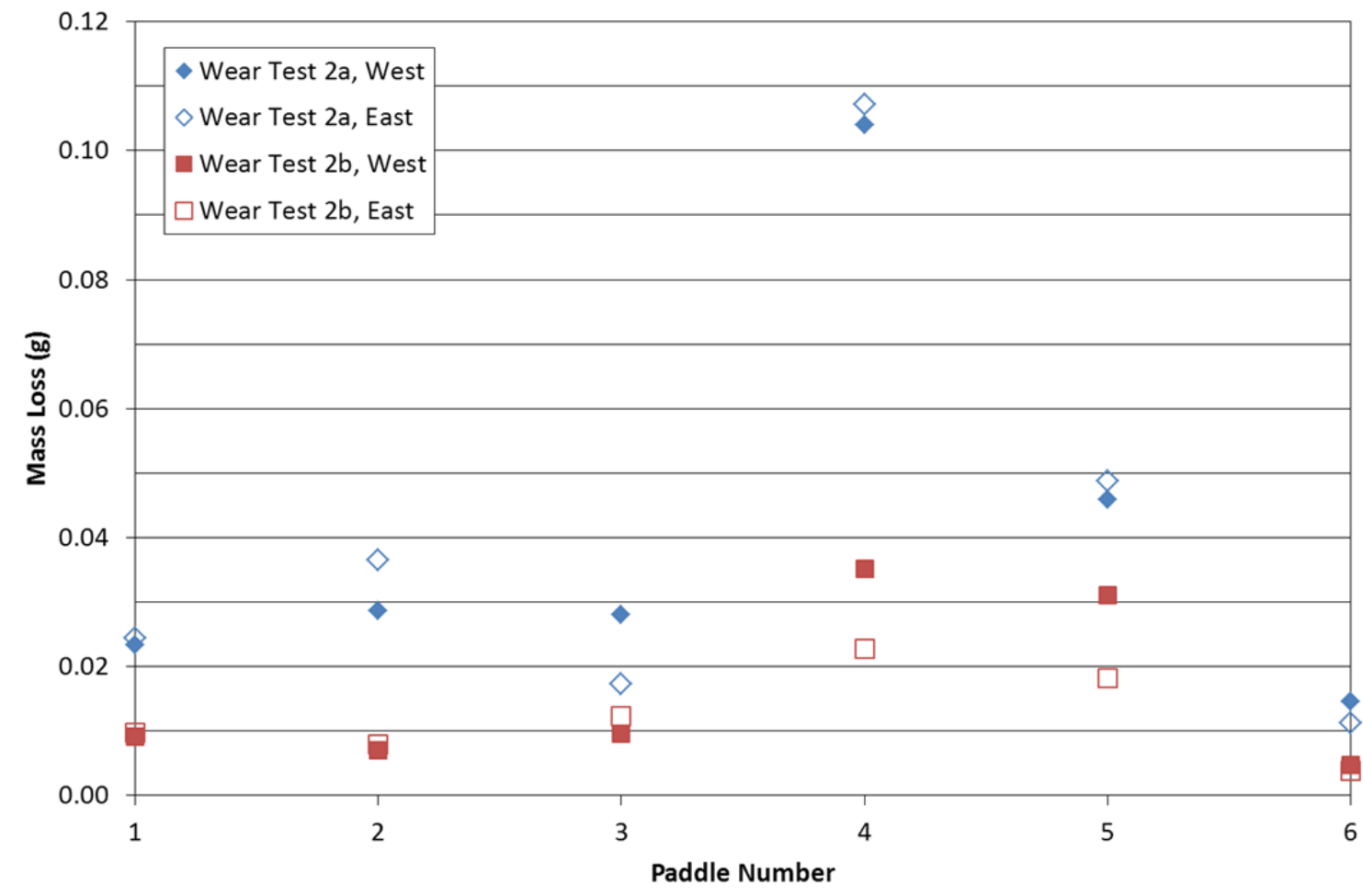

Figure 3-1. Mass loss for paddle pairs 1 - 6 after wear testing in the SPF mixer configuration (2a) and the alternate helical paddle configuration (2b).

\subsection{Paddle Contours}

When the mixer was opened at the end of wear test 2a, a significant amount of wear had visibly occurred at the tips of paddle pairs 4 and 5 and a lesser but noticeable amount of wear occurred on paddle pairs $1,2,3$, and 6 . The post-test paddle contours were plotted and, when compared to the pre-test contours, established a baseline wear pattern. Wear test $2 \mathrm{~b}$ was then conducted with the alternate paddle configuration. The pretest and post-test paddle contours were plotted and compared to the results of wear test 2a. The contour plots confirmed that a greater amount of wear occurred with the flat paddle configuration currently in the SPF mixer compared to the proposed helical paddle configuration. The extent of tip wear for paddle 4 on the east shaft (paddle \#35) from wear test 2a is shown in Figure 3-2. Paddle 4 on the east shaft (paddle \#52) from wear test $2 \mathrm{~b}$ is shown in Figure 3-3. Shown are the pre- and post-test contours. The contour 
measurement was taken at mid-height on the flat paddle and the lower height on the helical paddle. These heights represent the location of greatest wear. Contour plots for paddle pairs 1, 2, 3, 5, and 6 from both wear tests are shown in Appendix A.

Results from the contour plots are compiled in The following are observations from the contour measurements shown in Error! Not a valid bookmark self-reference.:

- The wear depth is approximately twice as great in wear test $2 \mathrm{a}$ stage $2 \mathrm{~b}$ paddles.

- Wear occurs mostly in the middle of the flat paddles.

- Wear occurs mostly at the trailing edge of the tip on both paddle designs as evidenced by polishing.

Table 3-1. The reductions in radial height, relative to the pre-test measurements, at the paddle tips for paddle pairs 4 and 5 from wear test 2a and $2 \mathrm{~b}$ are presented. The low, middle, and high contour data are presented. Pictures of the corresponding paddle tips are shown below each data set. A -0.002 inch "filter" was applied to the data to remove values greater than -0.002 inches (corresponding to the uncertainty of the measurement). The filter was applied to better illustrate the location of the greatest wear, an effect that tended to agree with the accompanying photo. Direction of paddle rotation is noted at the side of the data sets. The paddle numbers in columns $2-4$ are the unique identifiers given by SRNL for each paddle and do not represent the location in the mixer. The paddle numbers in column 1 correspond to the location in the mixer. 


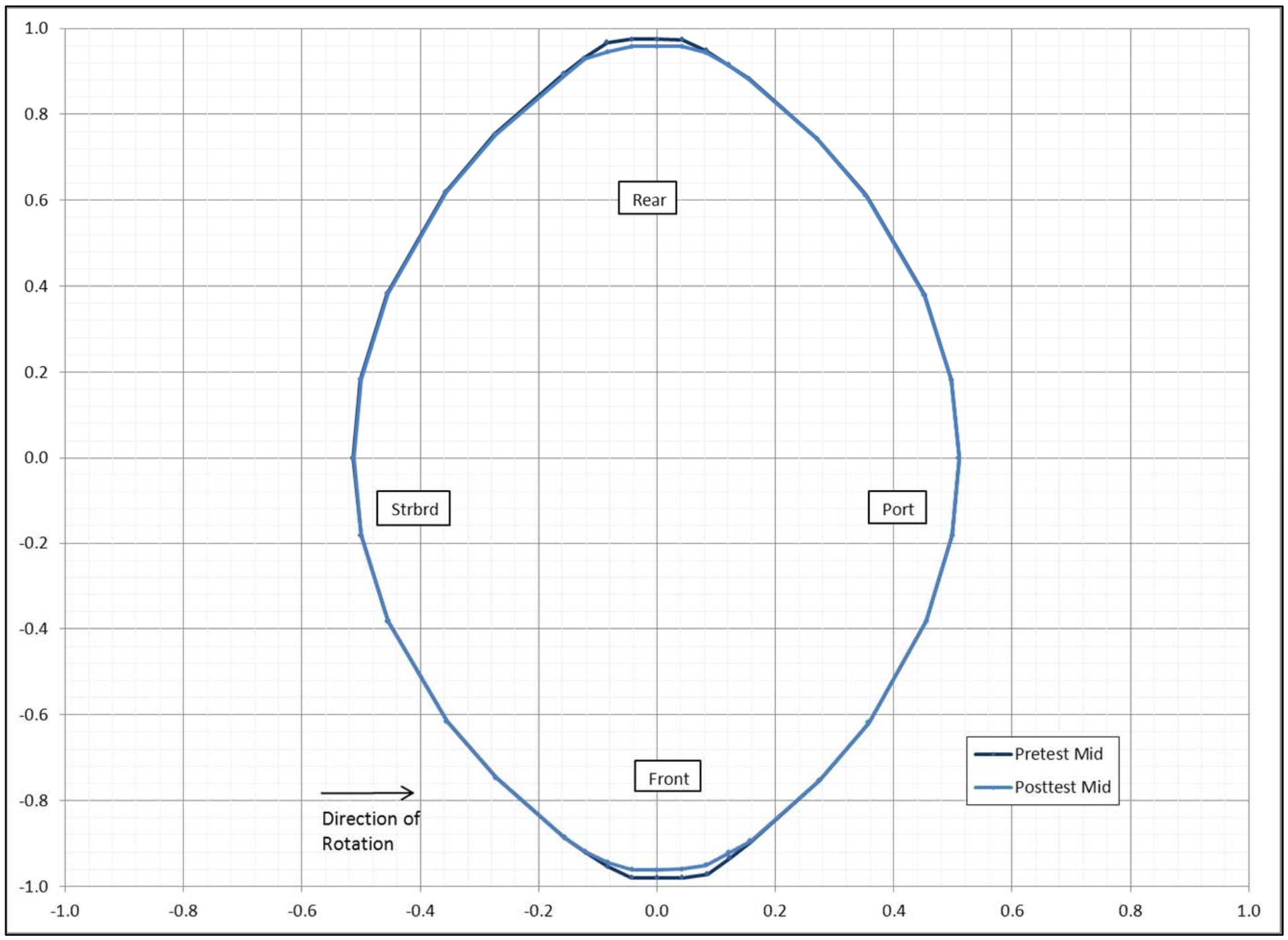

Figure 3-2. Pre- and post-test contour plot for wear test 2a, paddle 4 on the east shaft (flat paddle \#35). 


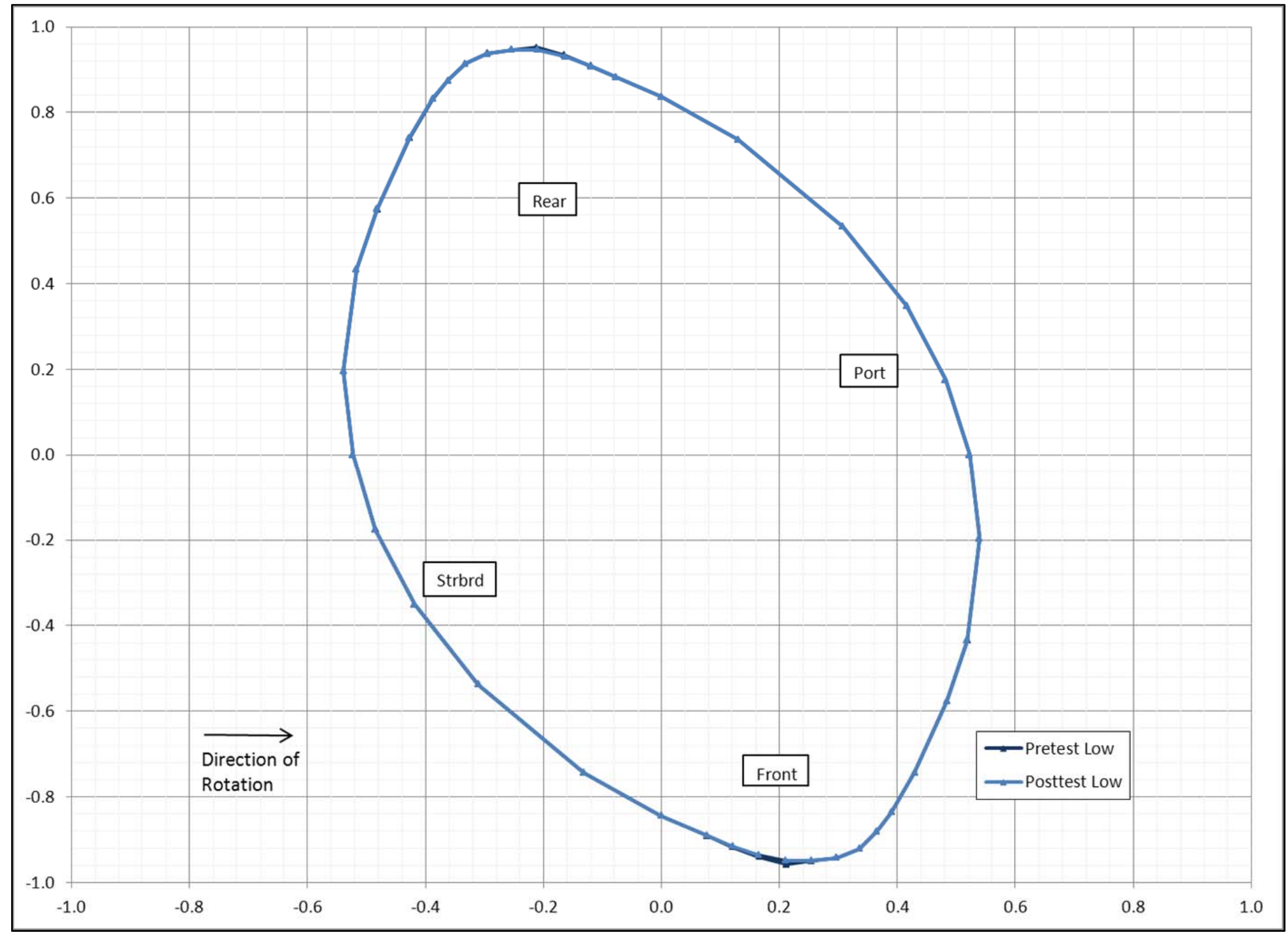

Figure 3-3. Pre-and post-test contour plot for wear test 2b, paddle 4 on the east shaft (helical paddle \#52) 
The following are observations from the contour measurements shown in Error! Not a valid bookmark self-reference.:

- The wear depth is approximately twice as great in wear test $2 \mathrm{a}$ stage $2 \mathrm{~b}$ paddles.

- Wear occurs mostly in the middle of the flat paddles.

- Wear occurs mostly at the trailing edge of the tip on both paddle designs as evidenced by polishing.

Table 3-1. Wear on paddle tips for paddle pairs 4 and 5 after testing.

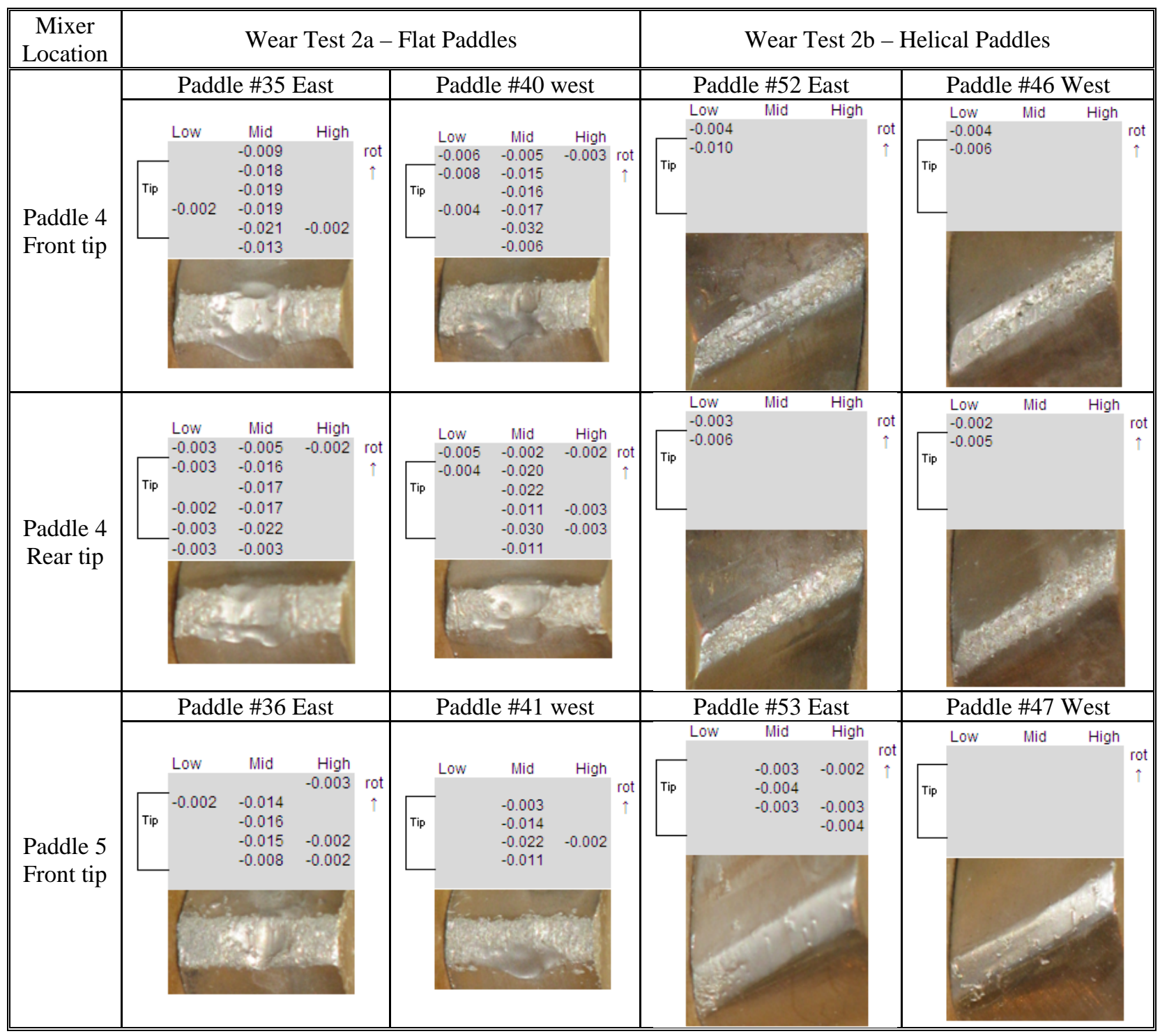




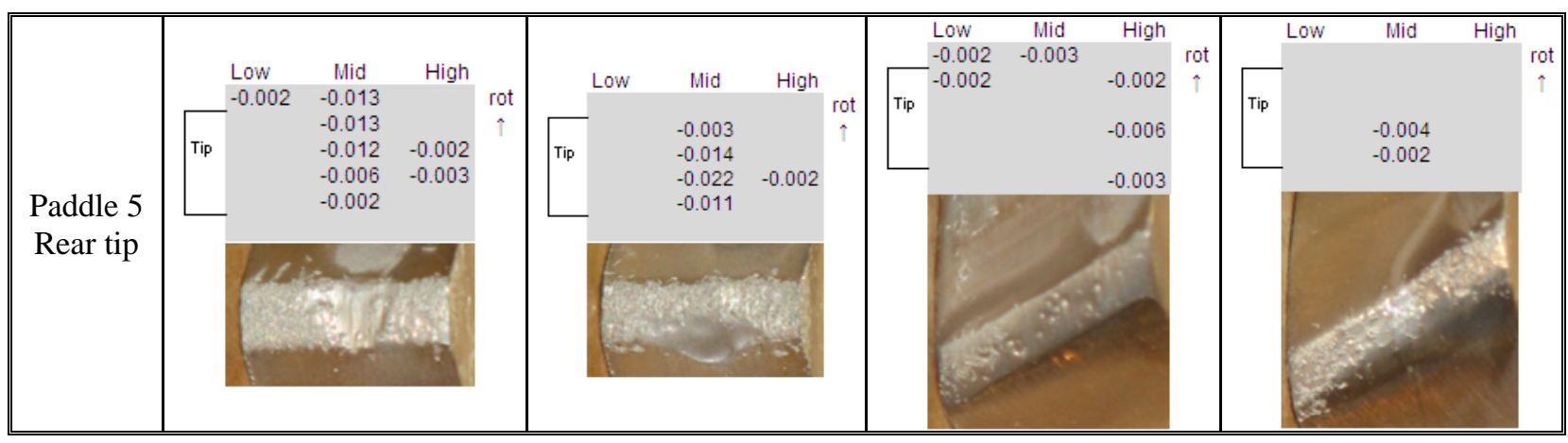

As shown in The following are observations from the contour measurements shown in Error! Not a valid bookmark self-reference.:

- The wear depth is approximately twice as great in wear test $2 \mathrm{a}$ stage $2 \mathrm{~b}$ paddles.

- Wear occurs mostly in the middle of the flat paddles.

- Wear occurs mostly at the trailing edge of the tip on both paddle designs as evidenced by polishing.

Table 3-1, the areas of wear on the flat and helical paddles are different. The majority of the wear occurs at the middle of the flat paddles, while the helical paddles wear more at the edges. Additional images of paddle pairs 1, 2, 3, and 6 are shown in 1.1.1.1.1Appendix B.

\subsection{Wear on the Mixer Barrel}

The mixer barrel is made of stainless steel and was not expected to show any significant wear within the time frame of this testing. However, wear is evident before the liquid inlet in the form of polishing (Figure 3-4). The polishing wear is evident on the upper housing clamshell and the lower housing clamshell primarily at paddle pairs 4 and 5. As shown in Figure 3-4, the paddles "mark" the inside of the barrel due to processing the grout. These marks are typical for both the 2-inch and 10-inch mixers. However, the polishing that occurs on the barrel around paddle pairs 4 and 5 is a result of the viscous grout mixture wearing the inside of the barrel as well as the paddles. 


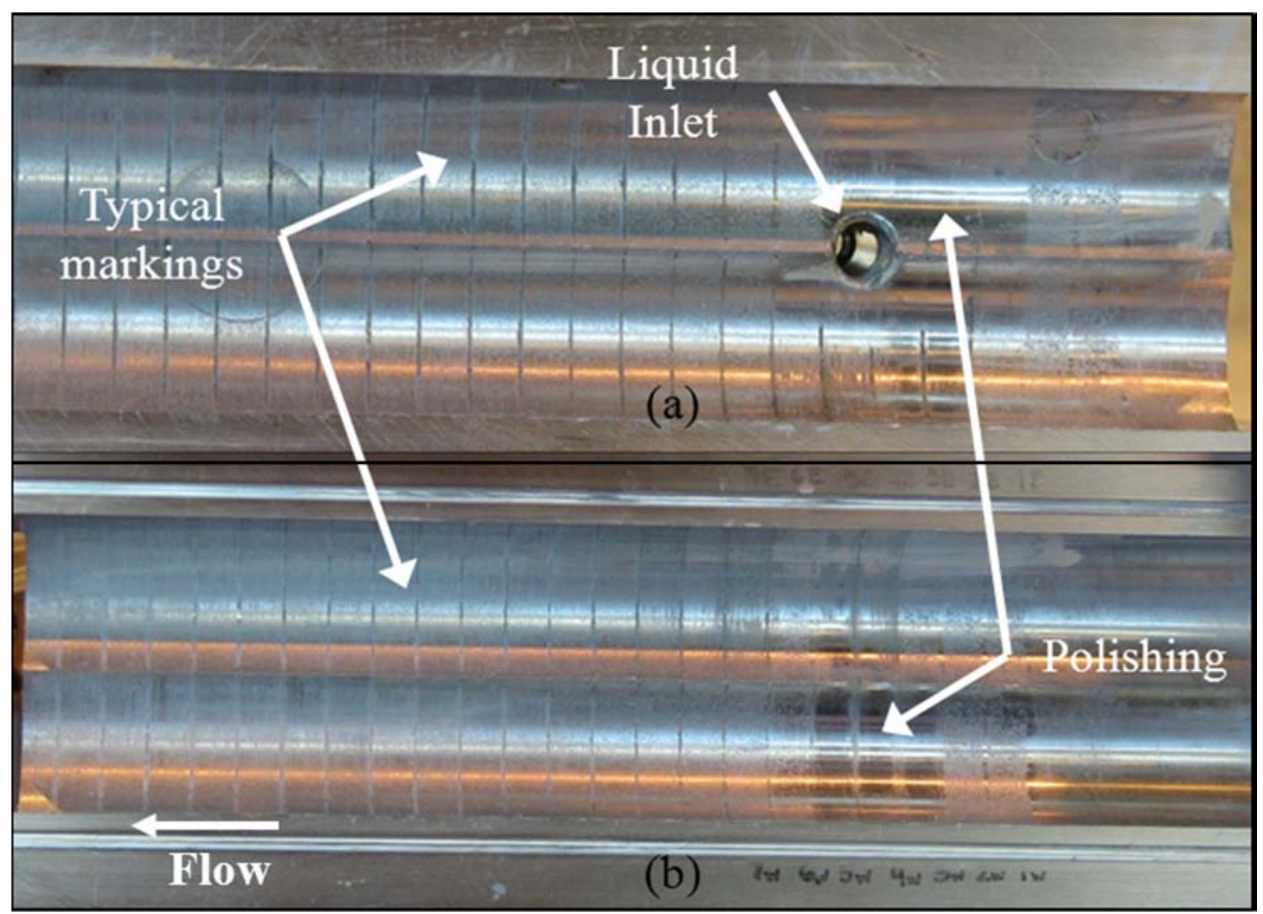

Figure 3-4. Wear on the inner diameter of the (a) upper and (b) lower clamshells.

Wear on the inside diameter of the mixer barrel can also reduce the self-wiping capability of the mixer paddles on the mixer barrel and lead to grout build up. As the gap between the barrel and the paddles increases, the more grout can build up over time and could affect the operation of the mixer. The grout buildup restricts the orifice for the dry feeds to enter the mixer and eventually leads to dry feeds backing up in the feed chute as demonstrated in the previous SPF mixer.,12 Similar wear patterns on the inside barrel of the mixer were also noted on the 10 -inch mixer (Figure 3-5). Since the mixer barrel cannot be reconfigured or replaced in the SPF, the method for mitigating wear on the barrel is to move the more viscous grout through the transition region as quickly as possible. Based on the results documented in sections 3.1 and 3.2, paddle pairs $1-6$ should be helical rather than flat paddles to aid in moving the grout through the mixer.

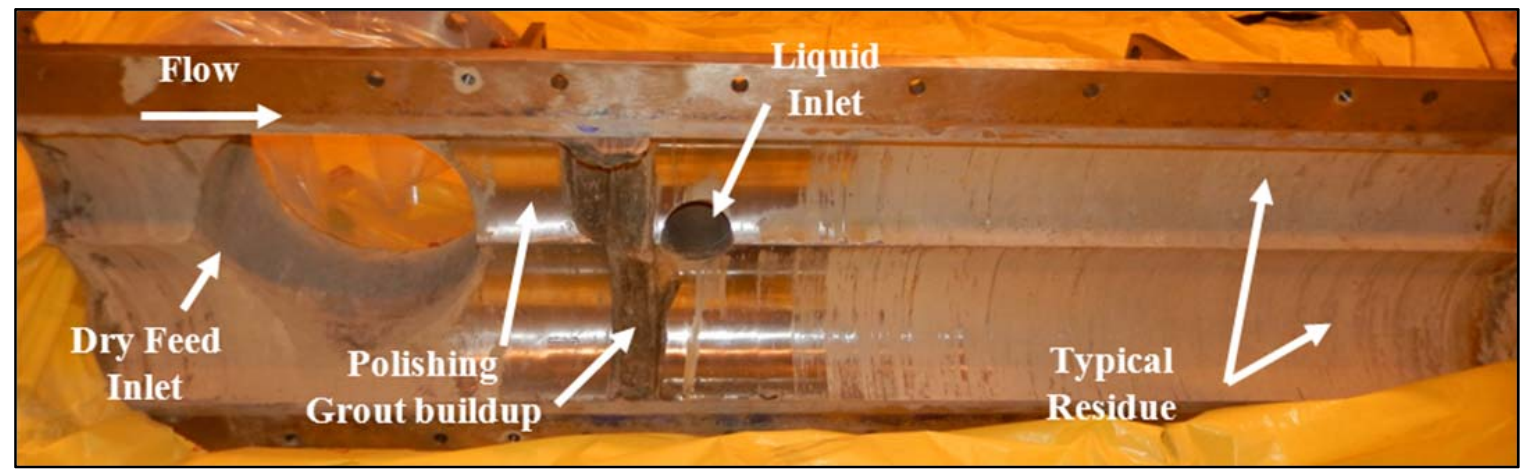

Figure 3-5. Wear on the inner diameter of the upper clamshell of the 10-inch SPF mixer. 


\subsection{Mixer Cleaning}

At the end of each wear test, the dry feeds were turned off and water was used to flush the mixer of any residual grout. The water entered the mixer through the liquid inlet. The flushing sequence lasted for several minutes until the liquid at the mixer discharge was clear. After flushing, the mixer was opened for more extensive cleaning and to remove the paddles for measurements. As shown in Figure 3-6, the location of the liquid inlet does not allow for sufficient cleaning of the mixer since residual grout remains on paddle pairs $1-4$. As the paddles continue to wear and the self-cleaning capability of the paddles is lost, the lack of sufficient flushing would allow grout to build up between the barrel and the paddles (Figure 3-5). The grout build up could also contribute to additional wear on the paddles during startup of the mixer.

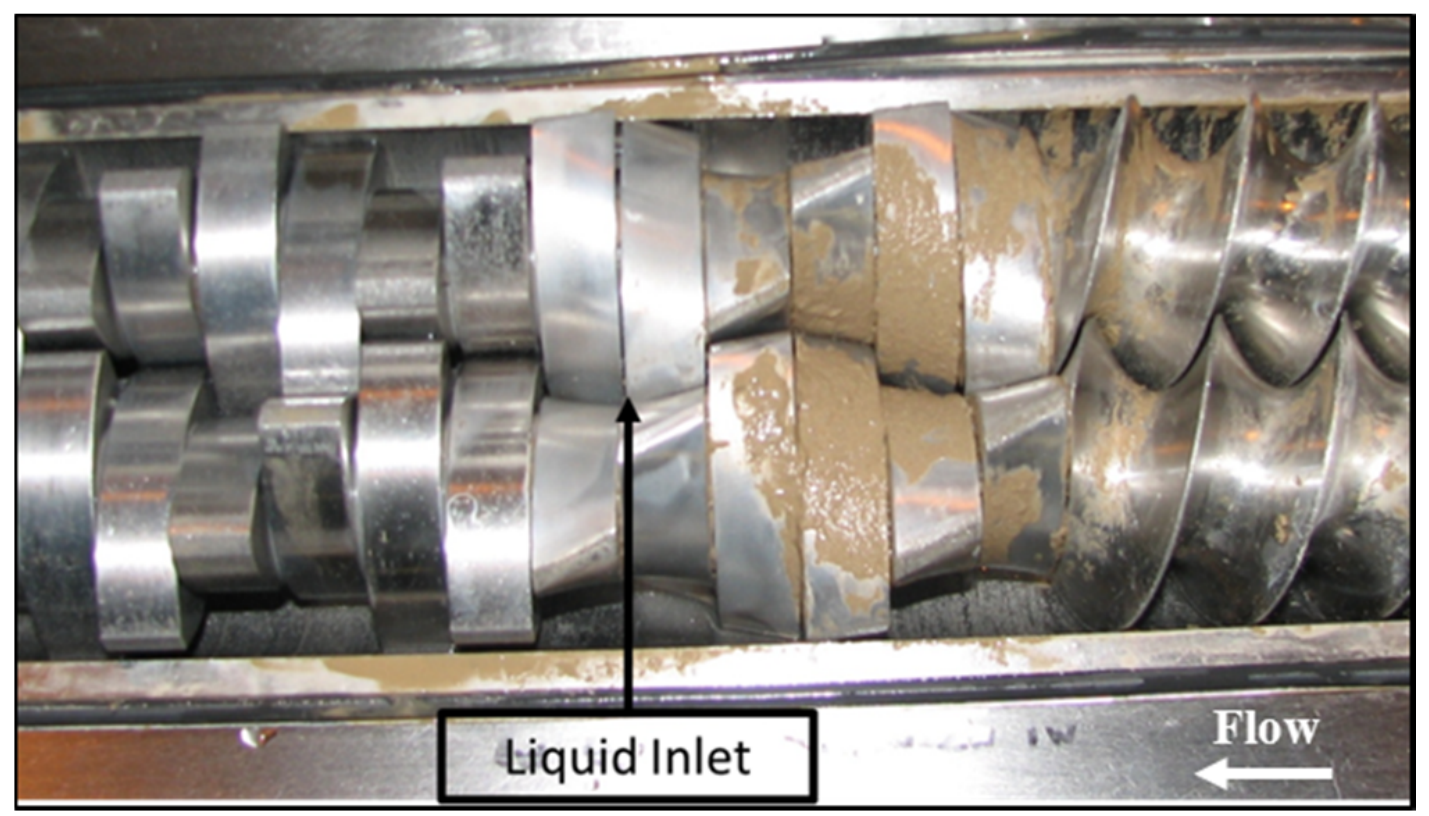

Figure 3-6. Extent of cleaning in the 2-inch mixer due to flushing using the liquid inlet.

As discussed in section 3.3, wear on the paddles and the mixer barrel causes grout to build up and reduces the area for the dry feeds to enter the mixer. Figure 3-7 shows the thickness of the grout build up (approximately 1.5 inches) on the inside of the upper clamshell as measured during the January 2013 mixer inspection. This reduces the barrel opening from approximately ten inches to approximately seven inches in diameter. As the paddles and mixer barrel continue to wear, and the grout buildup becomes thicker, dry feed throughput will decrease and eventually cause the process to shutdown. ${ }^{1,12}$ As shown in Figure 3-5, the grout build up occurs before the liquid inlet where flushing is minimal. Additional testing should be performed to determine an optimum position for additional liquid inlets into the mixer to aid in flushing at the end of processing and reduce or eliminate another potential source of wear in the mixer. 


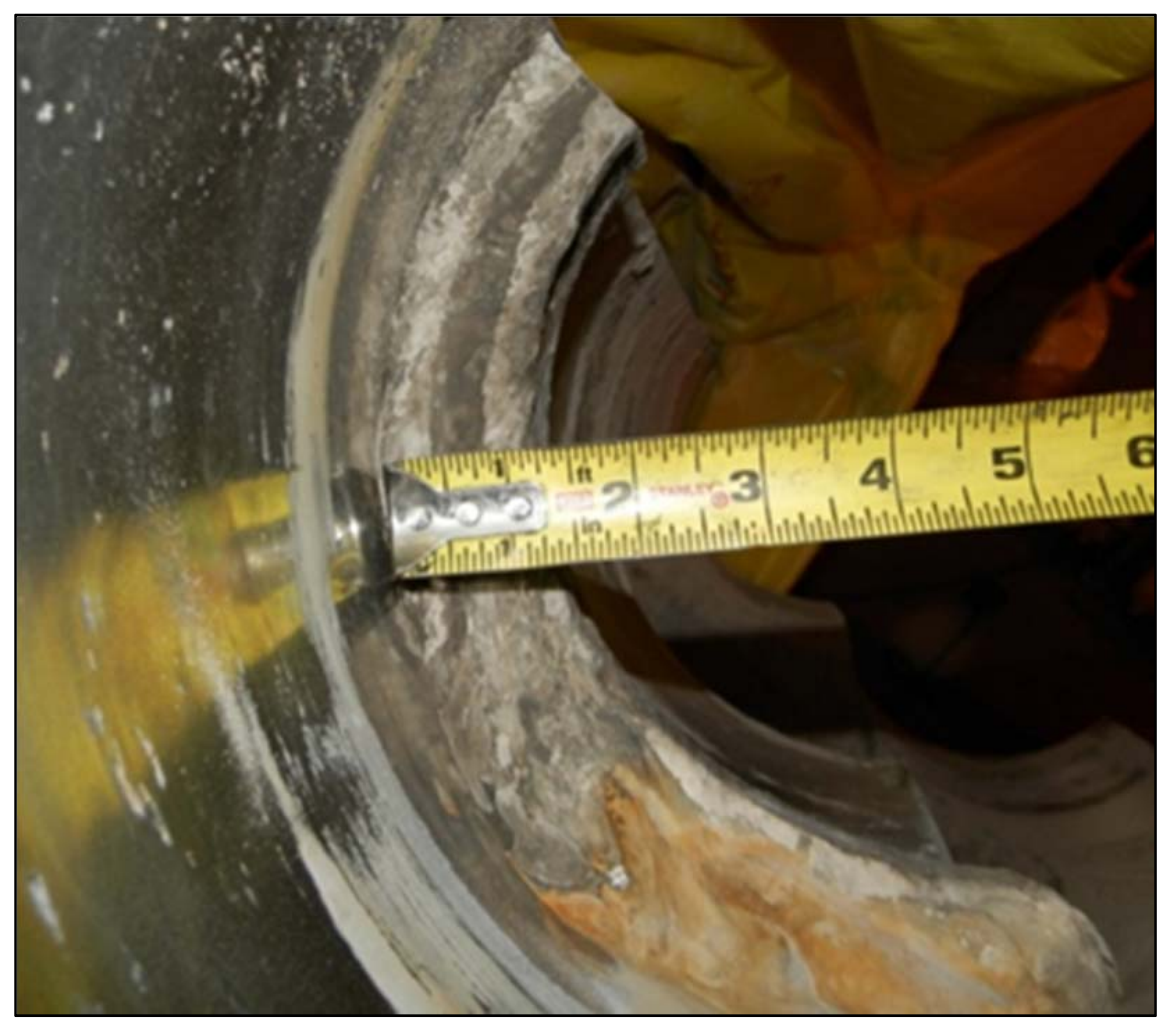

Figure 3-7. Thickness of grout build up (approximately 1.5 inches) in January 2013 on the inside diameter of the upper clamshell of the 10-inch SPF mixer.

\subsection{Rheology Results}

The rheological properties of the grout discharged from the mixer were measured to determine whether the fresh grout properties changed as a result of different paddle configurations. The plastic viscosity and yield stress measurements taken throughout testing of both the flat and helical paddle configurations are provided in Table 3-2. The average plastic viscosities for both wear tests are equal, showing that the paddle configuration does not affect the grout rheology. The average yield stress for wear test $2 \mathrm{~b}$ is slightly higher than that for wear test 2a; however, considering the standard deviation, the values are not statistically different.

Table 3-2. Rheological properties of the wear tests

\begin{tabular}{|c||c|c||c|c||}
\hline \hline \multirow{2}{*}{$\begin{array}{c}\text { Sample } \\
\text { Number }\end{array}$} & $\begin{array}{c}\text { Wear Test 2a - Flat Paddles } \\
\text { Plastic Viscosity } \\
\text { (cP) }\end{array}$ & $\begin{array}{c}\text { Yield Stress } \\
\text { (Pa) }\end{array}$ & $\begin{array}{c}\text { Wear Test 2b - Helical Paddles } \\
\text { Plac Viscosity } \\
\text { (cP) }\end{array}$ & $\begin{array}{c}\text { Yield Stress } \\
\text { (Pa) }\end{array}$ \\
\hline \hline 1 & 39.73 & 7.64 & 46.42 & 10.06 \\
\hline 2 & 39.57 & 7.33 & 39.38 & 8.29 \\
\hline 3 & 49.90 & 9.68 & 38.54 & 8.08 \\
\hline
\end{tabular}




\begin{tabular}{||c||c|c||c|c||}
\hline \hline 4 & 46.04 & 9.08 & 49.91 & 10.82 \\
\hline 5 & 49.61 & 9.95 & 38.83 & 7.90 \\
\hline 6 & 40.26 & 7.97 & 42.91 & 9.01 \\
\hline 7 & 40.26 & 7.97 & 48.20 & 11.39 \\
\hline 8 & 32.24 & 6.04 & 39.47 & 9.23 \\
\hline 9 & 45.54 & 9.06 & 48.65 & 11.90 \\
\hline 10 & 42.83 & 8.78 & 44.30 & 10.52 \\
\hline 11 & 44.89 & 8.25 & 43.59 & 10.52 \\
\hline 12 & 47.03 & 9.17 & 39.84 & 9.52 \\
\hline 13 & 59.98 & 11.72 & 50.19 & 11.76 \\
\hline 14 & 38.76 & 7.61 & 42.82 & 10.09 \\
\hline \hline Average & 44.05 & 8.59 & 43.79 & 9.94 \\
\hline Std. Dev. & 6.63 & 1.37 & 4.26 & 1.32 \\
\hline
\end{tabular}

\subsection{Conclusions and Recommendations}

The Saltstone Production Facility has a 10-inch Readco-Kurimoto continuous mixer that mixes the premix dry feeds and low-level waste salt solution to make fresh (uncured) saltstone. Inspection of the mixer in January 2013 showed significant wear on the third, fourth and fifth paddle pairs after the conveying augers. A 2-inch Readco-Kurimoto continuous mixer was used to test alternate paddle configurations for use in the 10-inch mixer to decrease the wear rate on the paddles.

Two wear tests were conducted to investigate a method of reducing wear on the mixer paddles. The first test (wear test 2a) had a paddle configuration similar to the currently installed 10-inch mixer in the SPF. This test established baseline wear. The second test (wear test $2 \mathrm{~b}$ ) had a reconfigured paddle arrangement that replaced the flat paddles with helical paddles for paddle pairs $2-6$ and aligned paddle pair 1 with the augers. The intent of the reconfiguration was to more effectively convey the partially wetted dry feeds through the transition region and into the liquid feed where paddle wear is reduced due to the grout being mixed at the intended water to premix ratio. The design of the helical paddles provides conveyance through the transition region to the liquid feed inlet. The alignment with the auger is aimed to provide a smoother transition (minimizing the discontinuity between the auger and paddle pair 1) into the downstream paddles.

A soft metal with low wear resistance (6000 series aluminum) was used for the wear testing paddles to minimize run time while maximizing wear rate. For the two paddle configurations tested using the scaled 2-inch Readco-Kurimoto continuous mixer, with the first six paddles after the augers replaced by the wear paddles and the remaining paddles were stainless steel. Since the 10-inch SPF mixer is designed with the liquid inlet centered over paddle pairs 5 and 6 , the scaled 2-inch mixer was configured the same way.

The wear rate from wear test 2a was approximately double the wear rate from wear test $2 \mathrm{~b}$ for paddle pairs 4 and 5 . For both configurations, there was little or no wear on paddle pairs 1, 2, 3 and 6 based on mass change, indicating that the un-wetted and fully wetted premix materials cause less wear than the partially wetted premix. Additionally, inspection of the wear surface of the paddles showed more deformation on the flat paddles than the helical paddles which was consistent with the wear rates. Aligning of the auger discharge flight with paddle pair 1 resulted in a lower wear rate paddle pair 1 rather than having them misaligned with the feed augers. 
During the paddle wear tests, polishing wear was observed on the inside barrel of the mixer. The polishing wear is evident on the upper housing clamshell and the lower housing clamshell primarily at paddle pairs 4 and 5, which is the transition region of the mixer. Wear on the mixer barrel increases the space between the paddles and the barrel, resulting in increased grout build up on the barrel. Since the mixer barrel cannot be reconfigured or replaced in the SPF, the method for mitigating wear on the barrel is to move the more viscous grout through the transition region as quickly as possible. In addition, the location of the liquid inlet does not allow for sufficient cleaning of the mixer since residual grout remains on paddle pairs $1-4$. As the paddles continue to wear and the self-cleaning capability of the paddles is lost, the lack of sufficient flushing would aid in grout build up between the barrel and the paddles which could eventually lead to decreased throughput capacity of the dry feeds.

Changing the paddle configuration from flat to helical resulted in no change to the rheological properties of the grout. Both tests produced a grout that is within the processing range of the SPF.

Based on the results of this testing, it is recommended for the currently installed SPF mixer that paddle pairs 1 through 6 be helical rather than flat, with the paddle pair 1 aligned with the feed augers in order to minimize the wear occurring in the SPF mixer.

\subsection{Future Work}

Based on the results of this testing, it is recommended that the mixer be inspected and critical measurements be taken whenever the SPF processing schedule allows in order to establish a wear rate of the 10 -inch mixer paddles. ${ }^{5}$ Based on these measurements, the lifetime of paddles in the transition region can be established in order to set up a maintenance schedule for the mixer. Since replacing the entire mixer is very expensive and time intensive, replacing the worn paddles after a specific time period would allow for planned shutdowns as well as process optimization such that the mixer throughput is not compromised.

In addition, further testing should be performed to determine an alternate liquid inlet location to better flush the mixer of residual grout at the end of processing. Sufficiently cleaning the mixer will help eliminate another potential source of wear. Another potential method for reducing the wear rate in the mixer is to reduce the mixer speed without affecting the throughput capacity. Since wear rate is a function of impact velocity of the grout and mixing paddles, testing could be done using the 2-inch mixer determine the optimum mixer speed to reduce wear but not impact facility operations. 


\subsection{References}

1. Reigel, M.M., Fowley, M.D., and Pickenheim, B.R., "Evaluation of Saltstone Mixer Paddle Configuration for Improved Wear Resistance," Savannah River National Laboratory, SRNL-STI-2012-00549, Revision 0, September 2012.

2. Staub, A.V., "FY2013 Testing of Bench Scale Saltstone," Savannah River Remediation, HLW-SSF-TTR-2013-0010, Revision 1, February 4, 2013.

3. Reigel, M.M. and Fowley, M.D., "Task Technical and Quality Assurance Plan for FY2013 Saltstone Testing Using the Scaled Continuous Processing Facility," Savannah River National Laboratory, SRNL-RP-2013-00128, March 2013.

4. Reigel, M.M. and Fowley, M.D. and Hansen, E.K. and Hera, K.R., et al., "Development and Implementation of a Scaled Saltstone Facility at Savannah River National Laboratory," Waste Management Symposia 2013, Vol., Pheonix, Arizona, 2013.

5. $\quad$ Reigel, M.M., Fowley, M.D., and Mickalonis, J.I., "Recommended Inspection Locations for the Saltstone Production Facility Mixer during Facility Outages," Savannah River National Laboratory, SRNL-L3100-2012-00202, Revision 0, November 28, 2012.

6. Mickalonis, J.I. and Torres, R.D., "Evaluation and Recommendation of Saltstone Mixer Auger/Paddles Materials of Construction for Improved Wear Resistance," Savannah River National Laboratory, SRNL-STI-2012-00379, Revision 0, July 2012.

7. Serrato, M.G., Fowley, M.D., and Reigel, M.M., "Initial Batch Run of the 2 inch Continuous Scaled Mixer," Savannah River National Laboratory, SRNL-L3100-201200042, March 29, 2012.

8. Desale, G.R., Gandhi, B.K., and Jain, S.C., "Slurry Erosion of Ductile Materials Under Normal Impact Condition," Wear, 264, 322-30 (2008).

9. $\quad$ Carter, A.R., Leita, J.N., Tihey, J.R., and Occhipinti, J.E., "Engineering Position for Saltstone Mixer Testing at Vendor Facility," Savannah River Remediation, SRR-WSE2011-00083, March 30, 2011.

10. Langton, C.A. and Burket, P.R. and Hansen, E.K. and Herman, D.T., et al., "Tank 50 Batch 0 Saltstone Formulation Testing," Savannah River National Laboratory, WSRCTR-2005-00498, January 30, 2006.

11. Hansen, E.K., "Physical Characterization of FY2004 Saltstone Simulant Slurries," Savannah River National Laboratory, WSRC-TR-2005-00365, Revision 0, December 2005.

12. Shah, S., "Evaluate/Recommend Saltstone Mixer Auger/Paddles Material of Construction for Improved Wear Resistance," Savannah River Remediation, HLW-SSF-TTR-20120001, October 27, 2011. 
SRNL-STI-2013-00523

Revision 0

Appendix A. Paddle Contour Plots 


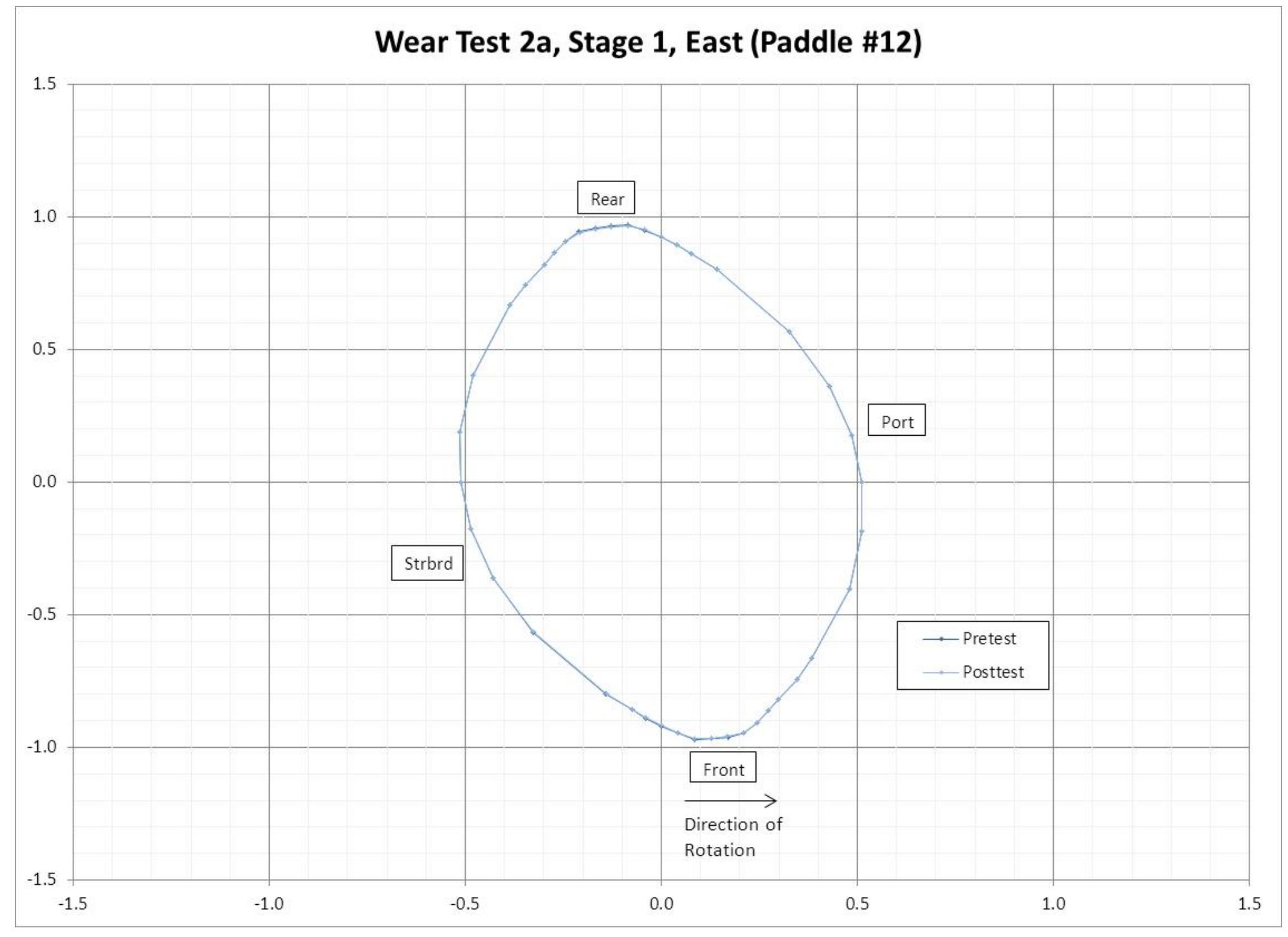

Figure A-1. Paddle 1, East, Mid Height, Test 2a, Paddle \#12, Helical 


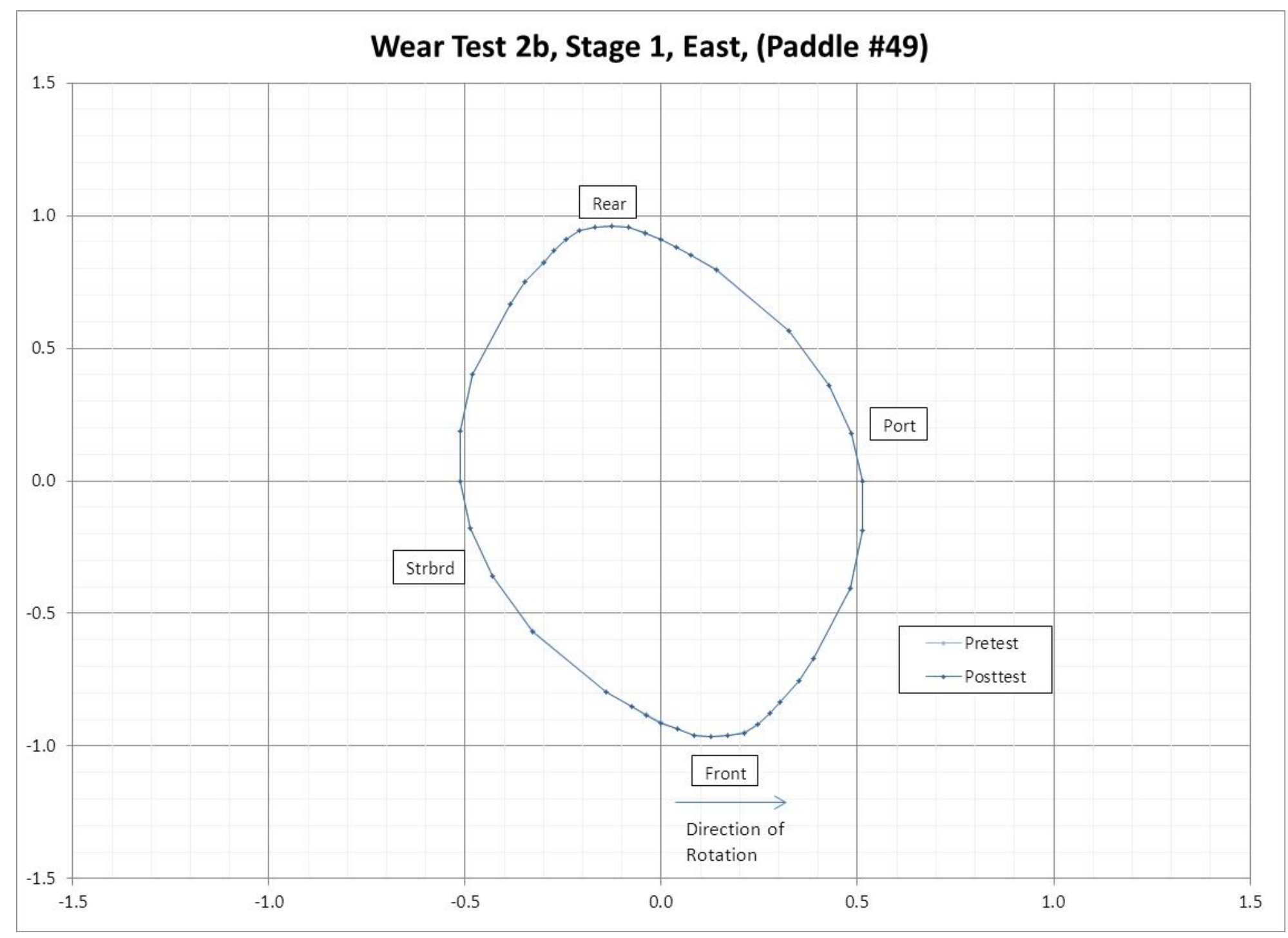

Figure A-2. Paddle 1, East, Mid Height, Test 2b, Paddle \#49, Helical. 


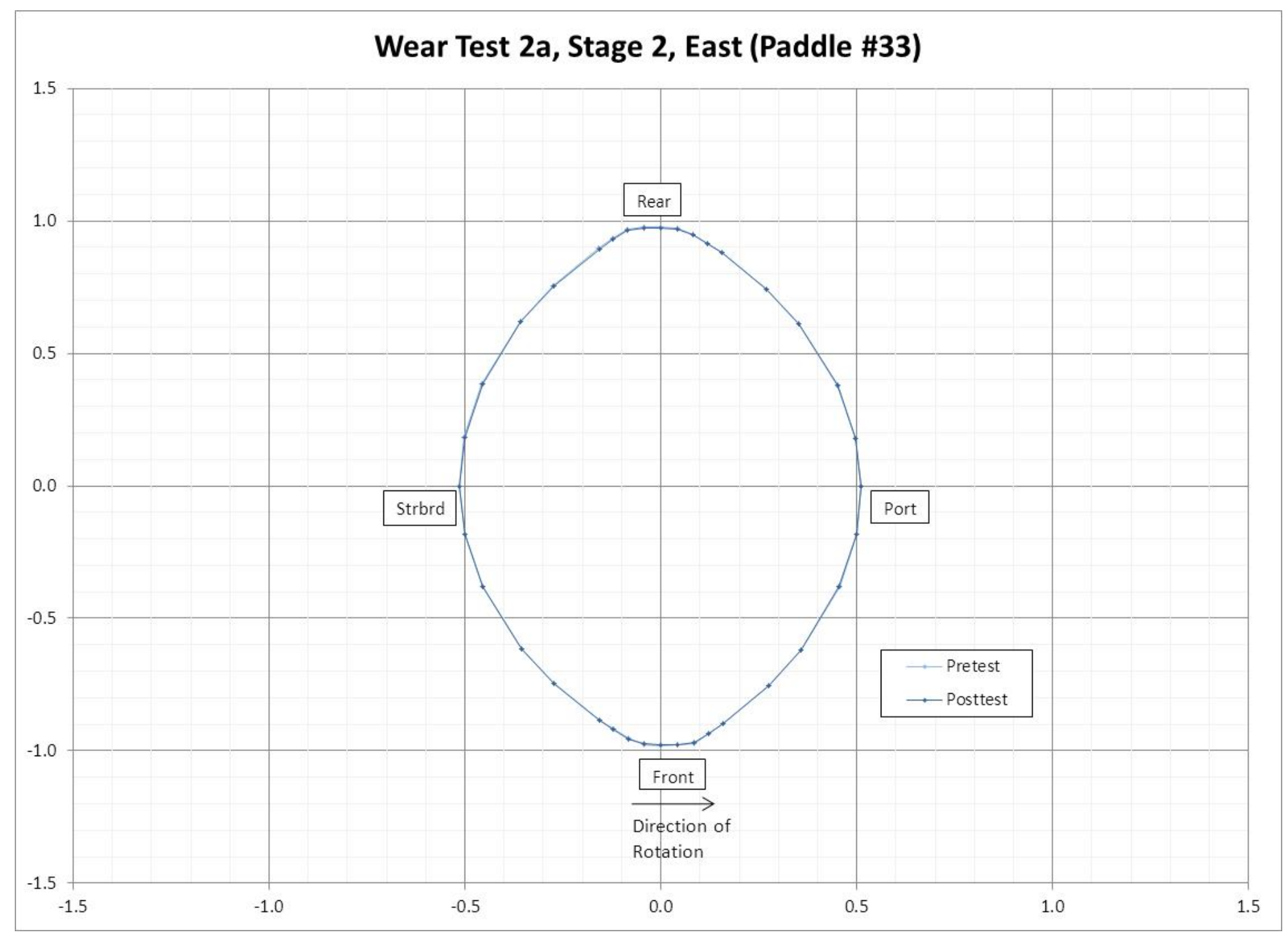

Figure A-3. Paddle 2, East, Mid Height, Test 2a, Paddle \#33, Flat 


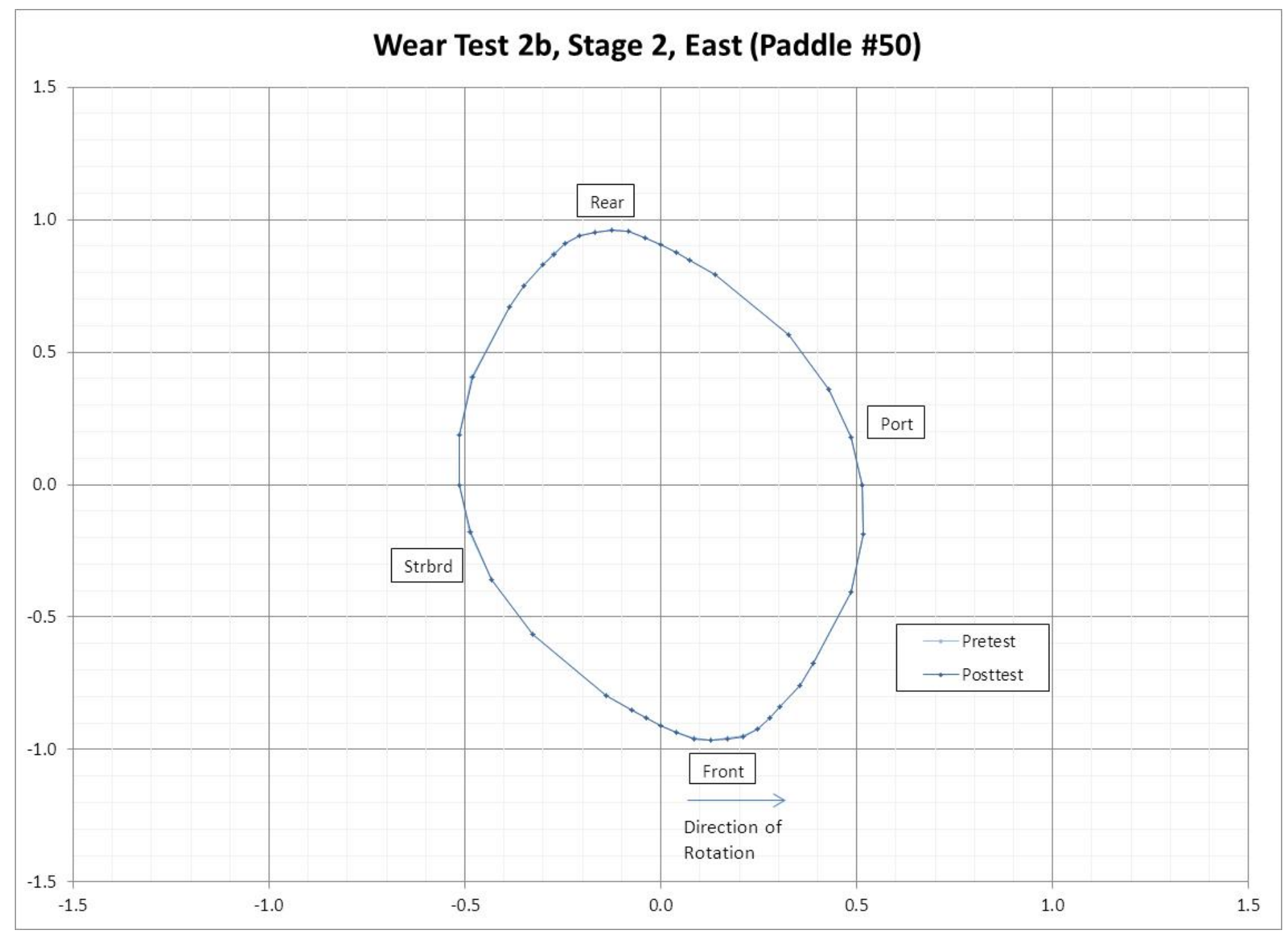

Figure A-4. Paddle 2, East, Mid Height, Test 2b, Paddle \#50, Helical 


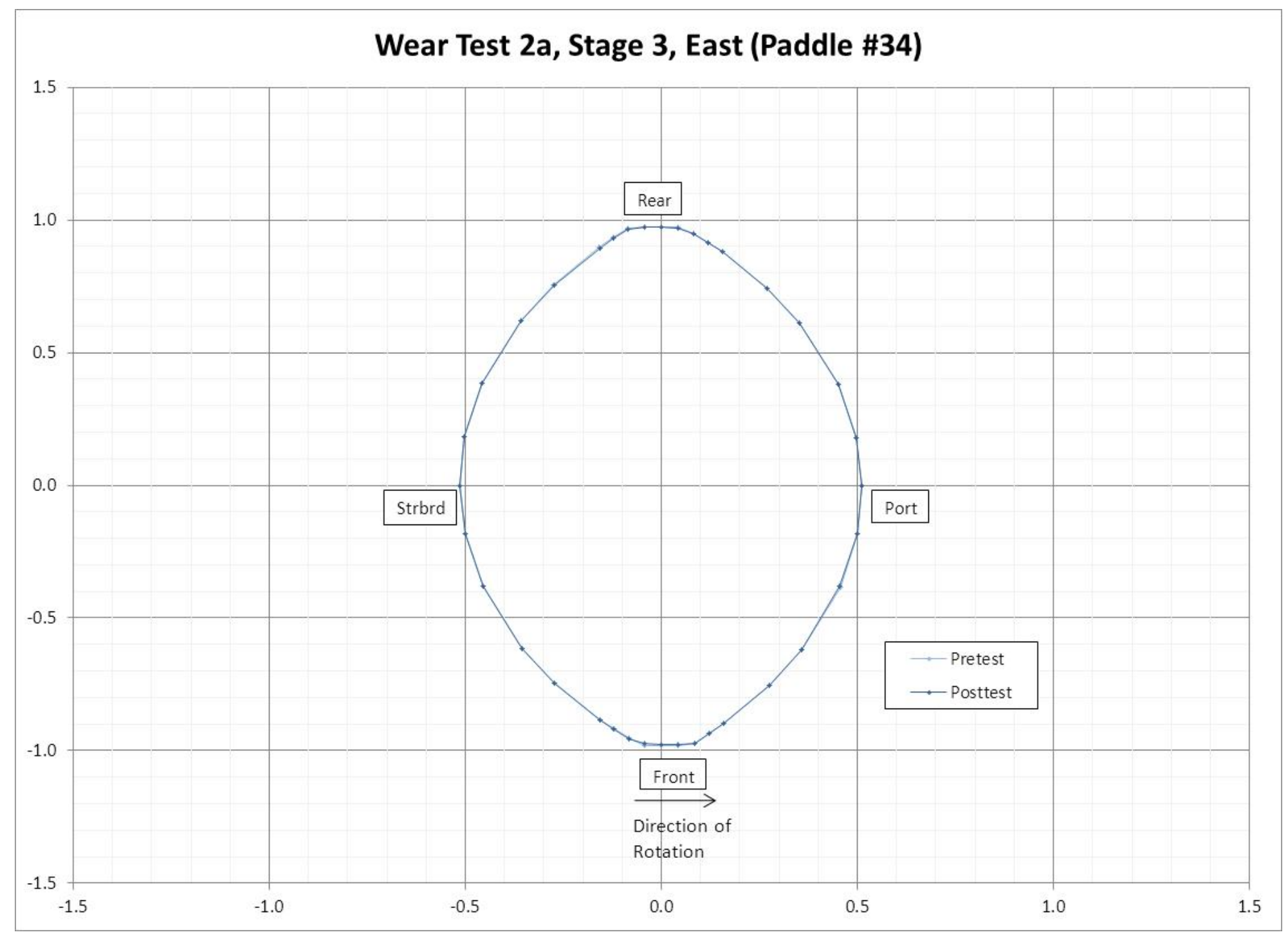

Figure A-5. Paddle 3, East, Mid Height, Test 2a, Paddle \#34, Flat 


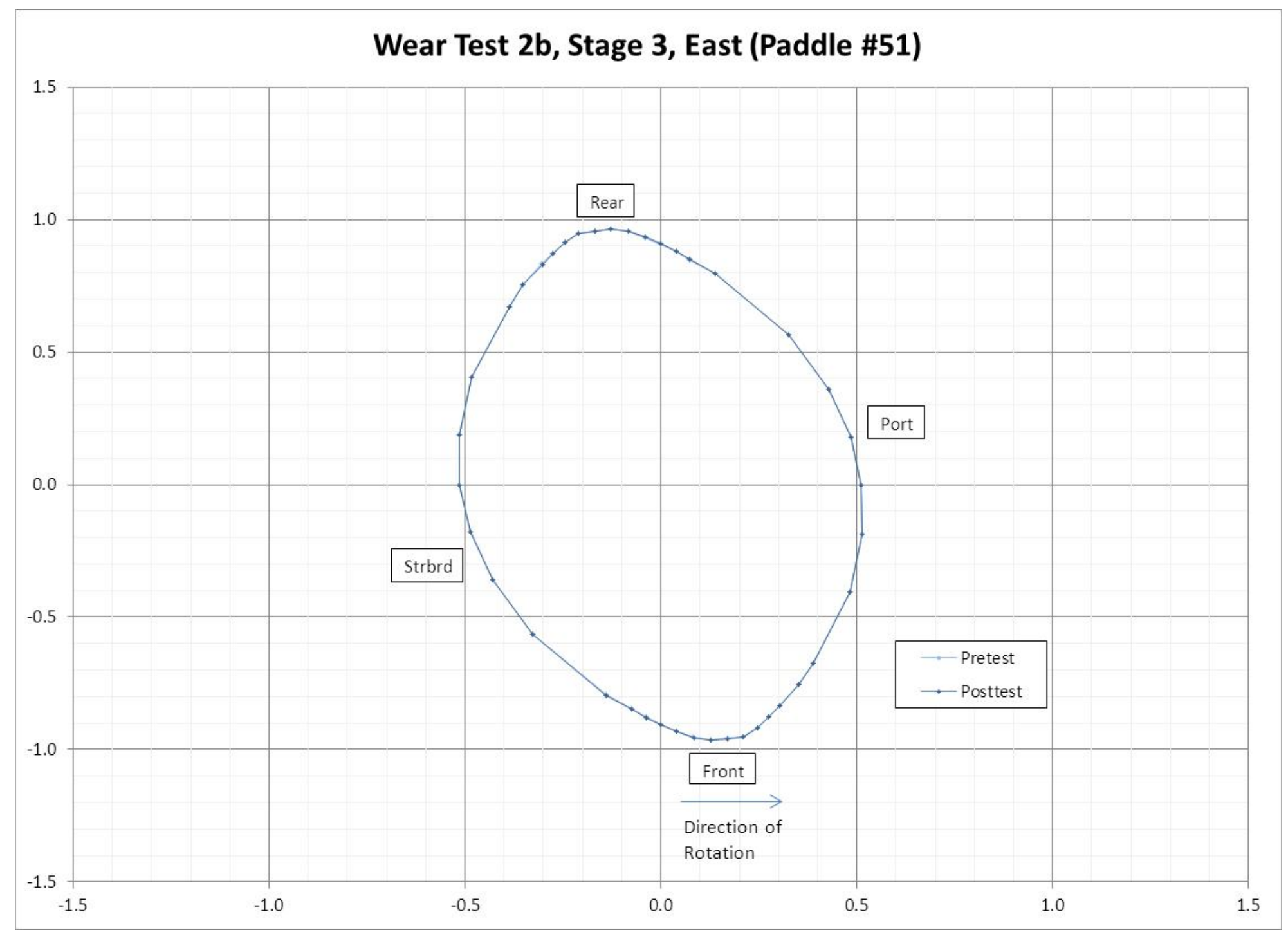

Figure A-6. Paddle 3, East, Mid Height, Test 2b, Paddle \#51, Helical 


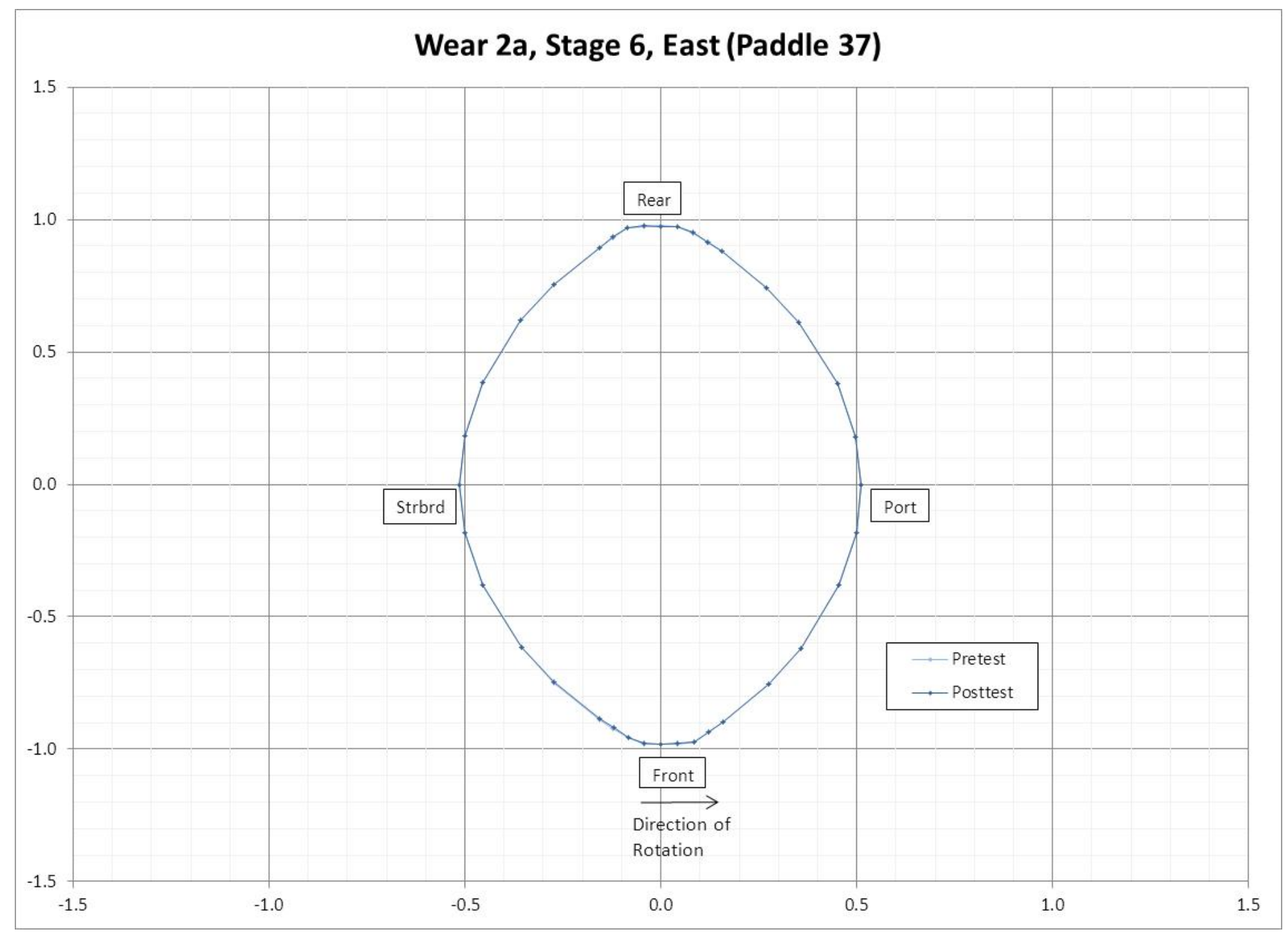

Figure A-7. Paddle 6, East, Mid Height, Test 2a, Paddle \#37, Flat 


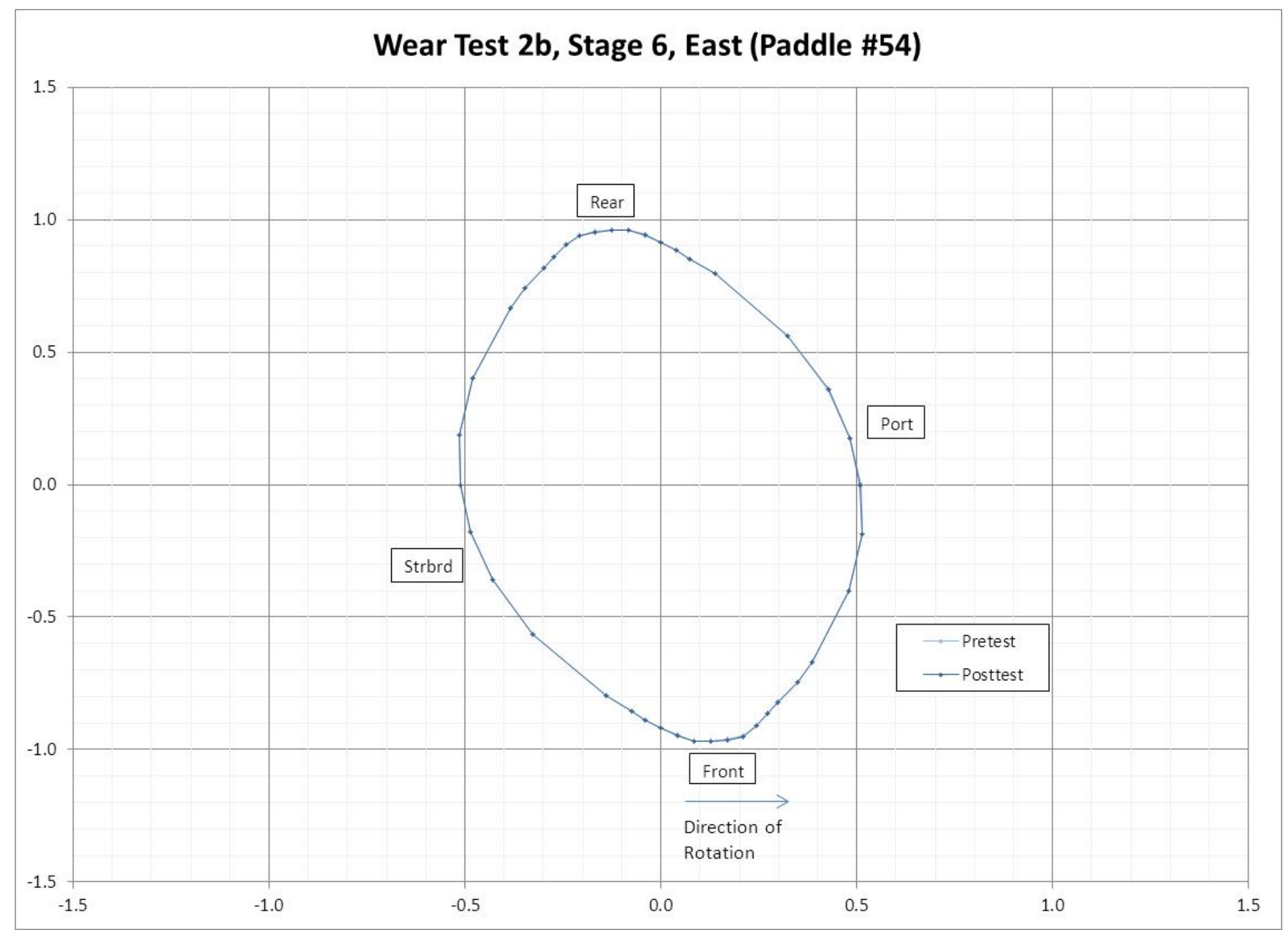

Figure A-8. Paddle 6, East, Mid Height, Test 2b, Paddle \#54, Helical 
SRNL-STI-2013-00523

Revision 0

Appendix B. Paddle Images Post Testing 
Paddle 1, East
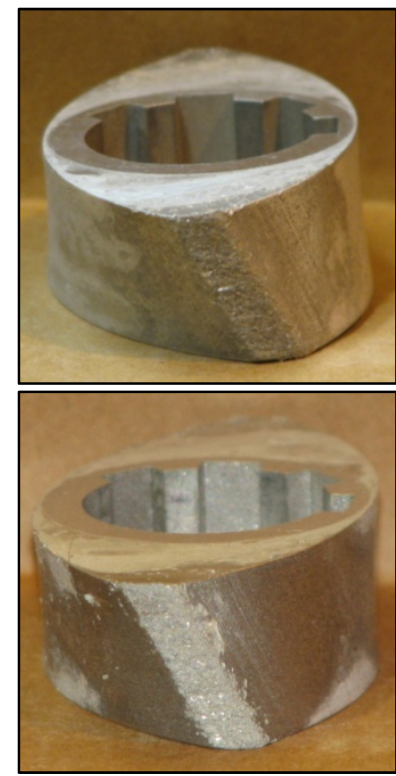

Paddle 1, West
Paddle 2, East
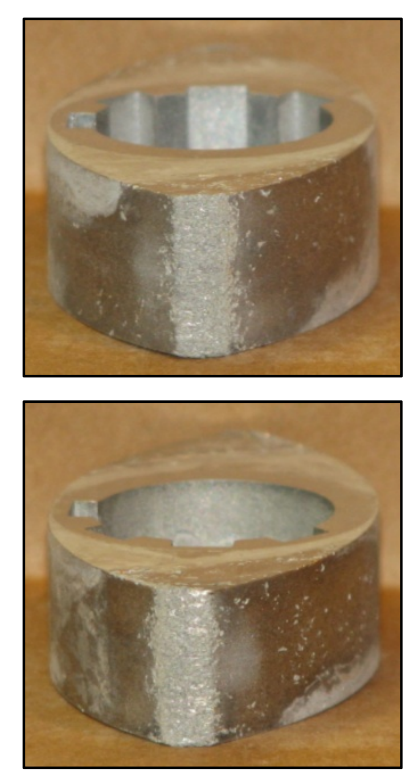

Paddle 2, West
Paddle 3, East
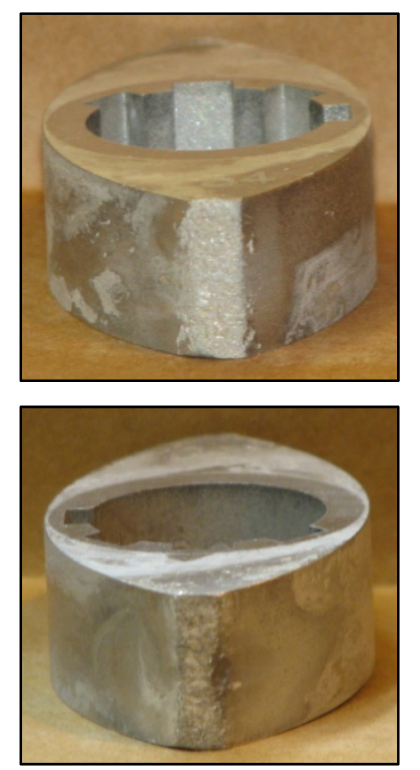

Paddle 3, West
Paddle 4, East
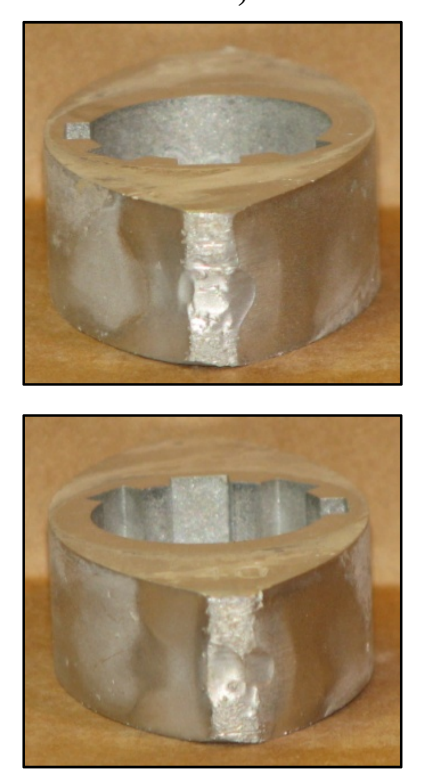

Paddle 4, West
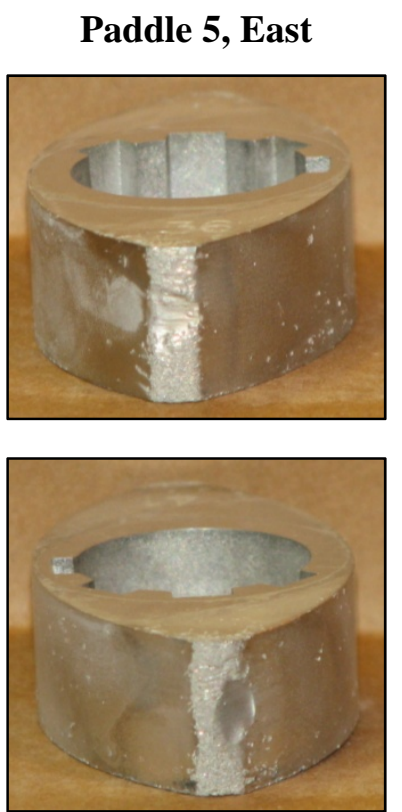

Paddle 5, West
Paddle 6, East
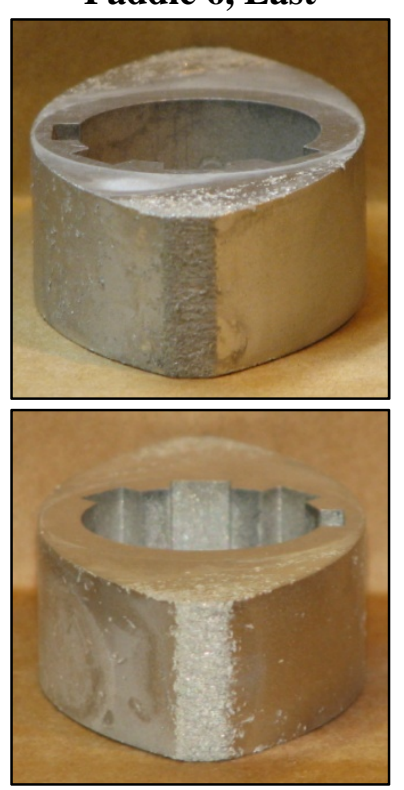

Paddle 6, West

Figure B-1. Images of paddle pairs post-testing for wear test 2a 
Paddle 1, East
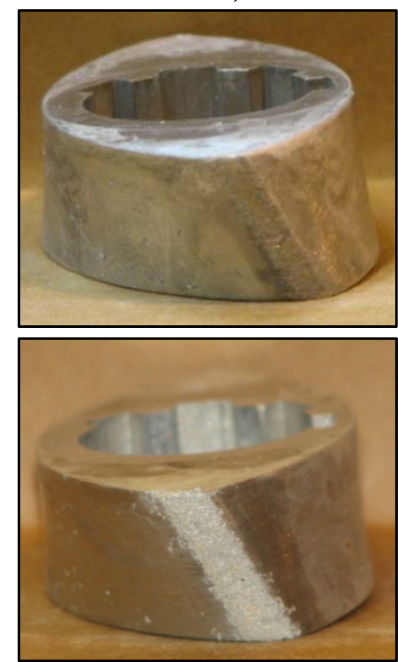

Paddle 1, West
Paddle 2, East
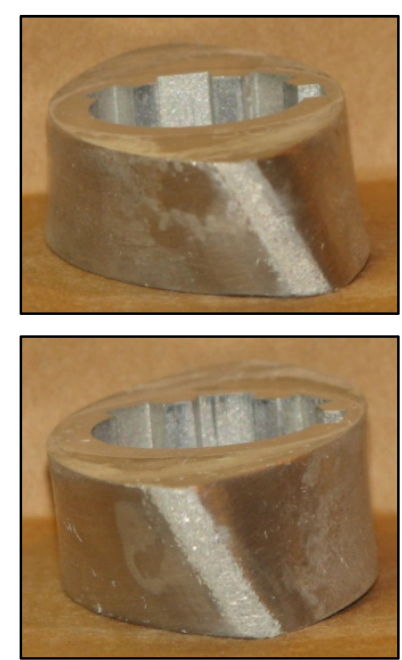

Paddle 2, West
Paddle 3, East
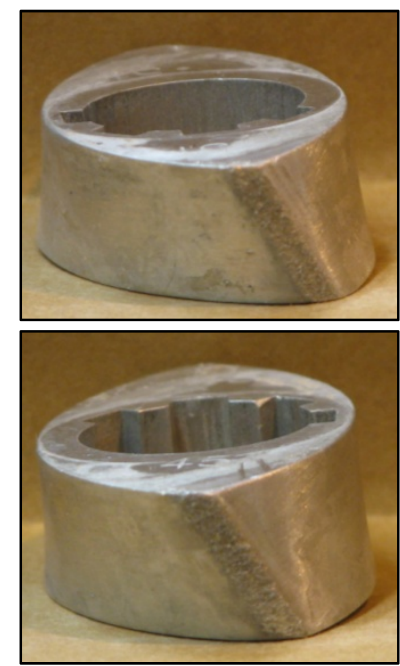

Paddle 3, West
Paddle 4, East
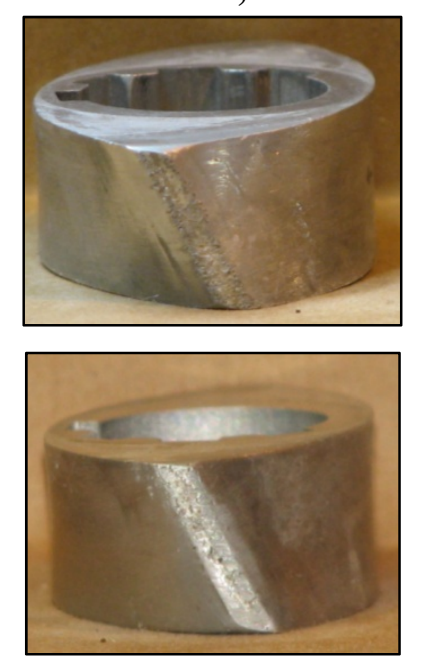

Paddle 4, West
Paddle 5, East
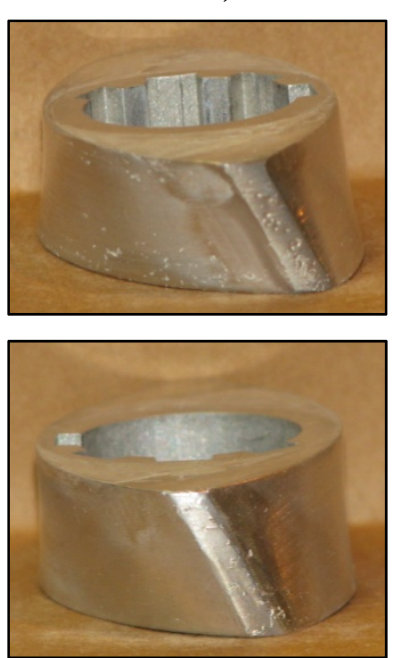

Paddle 5, West
Paddle 6, East
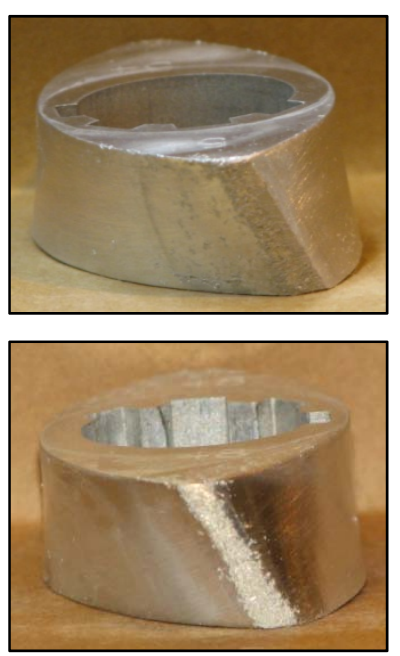

Paddle 6, West

Figure B-2. Images of paddle pairs post-testing for wear test $2 b$ 


\section{Distribution:}

S. L. Marra, 773-A

T. B. Brown, 773-A

D. R. Click, 999-W

S. D. Fink, 773-A

C. C. Herman, 773-A

E. N. Hoffman, 999-W

F. M. Pennebaker, 773-42A

W. R. Wilmarth, 773-A

J. S. Contardi, 704-S

V. Jain, 704-Z

J. N. Leita, 704-Z

A. V. Staub, 704-Z

S. C. Shah, 704-14Z

S. P. Simner, 249-8H

A. D. Cozzi, 999-W

K. M. Fox, 999-W

M. D. Fowley, 786-5A

E. K. Hansen, 999-W

K. J. Imrich, 773-A

C. A. Langton, 773-43A

P. R. Jackson, DOE-SR, 703-46A

Records Administration (EDWS) 